\title{
CASCA DE MARACUJÁ: ASPECTOS GERAIS, PROPRIEDADES TECNOLÓGICAS, APLICAÇÕES E PERSPECTIVAS
}

\author{
Alexia dos Santos Oliveira ${ }^{1}$, Hélia Lucila Malta ${ }^{2 *}$ \\ ${ }^{1}$ Graduanda em Engenharia de Alimentos pela Universidade Estadual de Feira \\ de Santana. \\ 2 Professora assistente do Departamento de Tecnologia da Universidade \\ Estadual de Feira de Santana. Feira de Santana, BA - Brasil. E-mail: hlmalta@uefs.br \\ Recebido em: 15/11/2021 - Aprovado em: 15/12/2021 - Publicado em: 30/12/2021 \\ DOI: 10.18677/EnciBio 2021D14 \\ trabalho licenciado sob licença Creative Commons Attribution-NonCommercial-NoDerivatives 4.0 International License.
}

\begin{abstract}
RESUMO
O maracujá amarelo (Passiflora edulis Sims $f$. Flavicarpa) é a espécie de maracujá mais comercializada no mundo. A contribuição mássica das cascas e sementes pode variar de acordo com o fruto de 40 a $60 \%$ e, por isso, tem se buscado aplicações para esses subprodutos, que compõem a geração de 54 mil toneladas de resíduos por ano. Esse trabalho apresenta uma revisão das principais aplicações da casca do maracujá (PFP - Passion fruit peel), foram utilizados artigos científicos e revisões bibliográficas prioritariamente publicados após o ano de 2016. Os resultados foram divididos em cinco temas principais: Elaboração de farinha de PFP e caracterização; Extração de pectina de PFP; Propriedades tecnológicas da PFP; Aplicações terapêuticas; Aplicações tecnológicas. A PFP possui alto teor de fibras em sua composição, por isso, tem sido muito utilizada na extração de pectina com metodologias convencionais e não convencionais. Além disso, PFP é "fonte" de Zinco e Cobre e tem "alto teor" de Magnésio, Manganês e Ferro, de acordo com os critérios da legislação brasileira. Geralmente, formulações com altos teores de PFP são menos aceitas sensorialmente. A presença de compostos cianogênicos também foi reportada, mas não foram encontrados relatos de intoxicação devido a seu uso. Os resultados desse trabalho sugerem que a PFP tem sido estudada majoritariamente para aplicações tecnológicas que visam seu alto teor de fibras, como elaboração de filmes, material para encapsulação, como ingrediente alimentício funcional.
\end{abstract}

PALAVRAS-CHAVE: Albedo; Pectina; Resíduos de processamento.

\section{PASSION FRUIT PEEL: GENERAL ASPECTS, TECHNOLOGICAL PROPERTIES, APPLICATIONS AND PERSPECTIVES}

\begin{abstract}
The yellow passion fruit (Passiflora edulis Sims f. Flavicarpa) is the most traded passion fruit species in the world. The mass contribution of peels and seeds can vary according to the fruit from 40 to $60 \%$ and, therefore, applications for these byproducts have been sought, which make up the generation of 54 thousand tons of waste per year. This work presents a review of the main applications of passion fruit peel (PFP), scientific articles and bibliographic reviews were used, mainly published after the year 2016. The results were divided into five main themes: Preparation of
\end{abstract}


PFP flour and characterization; Extraction of pectin from PFP; PFP's technological properties; Therapeutic applications; Technological applications. PFP has a high fiber content in its composition, therefore, it has been widely used in pectin extraction with conventional and unconventional methodologies. In addition, PFP is a "source" of Zinc and Copper and has a "high content" of Magnesium, Manganese and Iron, in accordance with the criteria of Brazilian legislation. Generally, formulations with high PFP contents are less sensorily accepted. The presence of cyanogenic compounds was also reported, but no reports of intoxication due to their use were found. The results of this work suggest that PFP has been studied mainly for technological applications aimed at its high fiber content, such as film making, encapsulation material, or as a functional food ingredient.

KEYWORDS: Albedo; Pectin; Processing Waste.

\section{INTRODUÇÃO}

O maracujá (Passiflora edulis) é um fruto originário da América Tropical e muito cultivado na América do Sul, especialmente no Brasil e Colômbia (GRISI et al., 2019). É uma das 525 espécies do gênero Passiflora, da família das Passifloraceae (IMIG et al., 2018). A maior importância econômica do fruto está no produto industrializado sob a forma de suco concentrado, embora também seja comumente empregado na formulação de sobremesas e outras bebidas (OLIVEIRA et al., 2016a; MONTEIRO et al., 2020; MENDES et al., 2021).

O Brasil teve um crescimento acentuado na produção de maracujá ao longo dos anos. Até o início da década de 1970, ainda não constava entre os principais produtores da fruta e em 2010, a produção já alcançava mais de 920 mil toneladas, que representavam 70\% da produção mundial (MELETTI, 2011; OLIVEIRA et al., 2016a). Mais recentemente, em 2020 a produção encontrava-se em torno de 690 mil toneladas, sob liderança dos estados Ceará e Bahia (IBGE, 2020).

O maracujá amarelo (Passiflora edulis Sims $f$. Flavicarpa) é a espécie de maracujá mais comercializada no mundo. Os resíduos do seu processamento são de aproximadamente 54 mil toneladas por ano (BEZERRA et al., 2019). A contribuição mássica das cascas e sementes pode variar de acordo com o fruto com valores reportados de 40 a 60\% (DIAS et al., 2011 ; OLIVEIRA et al., 2012; OLIVEIRA et al., 2016a; BORDIM et al., 2018). Os subprodutos do processamento de frutas são comumente empregados por produtores rurais para a suplementação da ração de seus rebanhos. No entanto, devido ao volume gerado, é de interesse econômico, científico e tecnológico que se considere seu potencial como ingredientes para o desenvolvimento de novos produtos (FERRARI et al., 2004).

Diante desse cenário, com perspectiva de agregar valor aos subprodutos do processamento e reduzir o impacto ambiental causado pela geração de resíduos, vários autores (REIS et al., 2018; FERREIRA; TARLEY 2021; CAO et al., 2021) têm se dedicado ao estudo de caracterização e de aplicações tecnológicas da casca do maracujá (PFP - Passion fruit peel). Neste trabalho, adotou-se a convenção de que a casca é composta pelo mesocarpo e epicarpo, parte branca esponjosa e parte serosa do exterior do fruto. Já o albedo é apenas parte esponjosa, o mesocarpo (OLIVEIRA et al., 2016a; BEZERRA et al., 2019). Alguns estudos trabalham com a casca inteira, enquanto outros, especificamente com o albedo, essa distinção pode ser de grande influência em determinadas propriedades tecnológicas e nutricionais.

Tem se observado que a casca, principalmente a parte do albedo, quando processada, pode ser utilizada pela indústria como matéria prima fonte de fibras alimentares, niacina (vitamina B3), ferro, cálcio e fósforo e compostos antioxidantes 
que têm funções essenciais no funcionamento do organismo (SILVA et al., 2016; LIMA et al., 2016; NOVAES et al., 2017; BORDIM et al., 2018).

$\mathrm{Na}$ última década, vários estudos relataram suas propriedades funcionais, especialmente, o conteúdo de fibra alimentar e capacidade antioxidante (CAZARIN et al., 2014; SILVA et al., 2014; SULERIA et al., 2020; CAO et al., 2021). Essas características têm impulsionado pesquisas que avaliam seus efeitos em parâmetros de saúde, como aqueles relacionados à ação anti-hiperglicêmica em animais (KANDANDAPANI et al., 2015; LIMA et al., 2016) e humanos (QUEIROZ et al., 2012). Dessa forma, também tem sido utilizada na obtenção de produtos direcionados para pessoas que necessitam aumentar a ingestão de fibras para prevenir doenças gastrointestinais, cardíacas e diabetes (SOUSA et al., 2020; FERREIRA; TARLEY, 2021)

Motivadas por esse contexto, esse trabalho de revisão teve como objetivo a análise das publicações nos últimos anos que tratam das pesquisas sobre a elaboração de farinha de PFP, apresentar dados físico-químicos da PFP, sua aplicação como fonte de pectina, produtos terapêuticos, como ingrediente tecnológico ou de produtos alimentícios funcionais, além de trazer uma breve discussão sobre seu conteúdo de compostos cianogênicos.

\section{MATERIAL E METODOS}

Esse estudo é uma revisão da literatura a respeito da utilização de casca de maracujá (PFP). Como critério de inclusão nesse trabalho foram selecionados apenas artigos científicos e revisões bibliográficas, sendo priorizados os publicados a partir de 2016. As bases de dados utilizadas para a busca foram: Science Direct, Scielo, Portal CAPES, Google Acadêmico, Springer. A busca se iniciou com artigos relacionados às palavras chave "passion fruit peel", "passion fruit albedo", "casca de maracujá", "albedo de maracujá". Foram selecionados estudos de desenvolvimento de produtos e caracterização de amostras de casca, albedo, farinha e produtos elaborados com a PFP.

\section{RESULTADOS}

Com base nas publicações encontradas, foram divididos cinco tópicos principais: Elaboração de farinha de PFP e caracterização; Extração de pectina de PFP; Propriedades tecnológicas da PFP; Aplicações terapêuticas; Aplicações tecnológicas. Ao avaliar os artigos e revisões bibliográficas selecionados para compor essa revisão, foi percebido que geralmente as metodologias de uso de PFP produzem a farinha que posteriormente é empregada para duas principais finalidades: uso tecnológico/terapêutico, ou como etapa que antecede a extração de seus componentes. Portanto, nesse trabalho a elaboração de farinha de PFP será abordada no primeiro tópico.

\section{A) METODOLOGIAS PARA OBTENÇÃO DE FARINHA DE CASCA (PFP)}

A produção de farinha de casca, ou apenas de albedo de maracujá, costuma ser realizada de acordo com metodologias similares. Alguns autores reportam o início do processo pela sanitização com hipoclorito de sódio (SILVA et al., 2016) ou com a lavagem dos frutos (SEIXAS et al., 2014; OLIVEIRA et al., 2016a). Em seguida, remove-se a polpa, manualmente ou não (LÓPEZ-VARGAS et al., 2013; SILVA et al., 2016; OLIVEIRA et al., 2016a).

Silva et al. (2016) em sua metodologia relatam o cozimento do albedo durante 5 min em panela de pressão. Tanto OLIVEIRA et al. (2016a) quanto Seixas et al. 
(2014) realizam o processo de branqueamento para inativação enzimática e diferiram no binômio tempo/ temperatura de suas metodologias que consistiam em $100^{\circ} \mathrm{C} / 3 \mathrm{~min}$ e $97^{\circ} \mathrm{C} / 3 \mathrm{~min}$, respectivamente. Além disso, no primeiro trabalho o procedimento foi interrompido em banho de gelo, enquanto no segundo foi resfriado à temperatura ambiente por 15 minutos.

Alguns autores adotam suas metodologias de trabalho apenas com o albedo do maracujá, removendo o epicarpo (LÓPEZ-VARGAS et al., 2013; SILVA et al., 2016). Silva et al. (2016) fizeram a consideração de que a naringina (flavonoide causador de amargor) presente no albedo poderia ser removida com imersão em água durante $24 \mathrm{~h}$. Por isso, fizeram esse tratamento em sistema refrigerado com $200 \mathrm{~g} / \mathrm{L}$ de água que era trocada a 4 horas. A metodologia de López-Vargas et al. (2013) incluía lavagem com 5 litros de água a $45^{\circ} \mathrm{C}$ por $\mathrm{kg}$ de albedo com agitação durante oito minutos, mas não há menção à naringina. Após esse tipo de procedimento, a água é retirada por prensagem, drenagem ou algum outro procedimento com essa finalidade (LÓPEZ-VARGAS et al., 2013; SILVA et al., 2016).

A etapa do processo em que mais foram observadas variações foi a secagem. López-Vargas et al. (2013) e OLIVEIRA et al. (2016a) realizaram a secagem a $60^{\circ} \mathrm{C}$ por $24 \mathrm{~h}$ e $72 \mathrm{~h}$ respectivamente. Bordim et al. (2018) e Seixas et al. (2014) não reportam o tempo de suas secagens a $63^{\circ} \mathrm{C}$ e a $50^{\circ} \mathrm{C}$ respectivamente, mas procederam até a obtenção de peso constante. Silva et al. (2016) fizeram secagem com variações tempo/ temperatura variando de $50^{\circ} \mathrm{C}$ por $21,5 \mathrm{~h}$ a $80^{\circ} \mathrm{C}$ por $9,5 \mathrm{~h}$. Martins et al. (2019) avaliaram a eficiência de correlações matemáticas na secagem, variando a temperatura de 30 a $70^{\circ} \mathrm{C}$. Seus resultados sugerem que a modelagem do processo pode exercer influência na composição da PFP seca, como acidez titulável e teor de ácido ascórbico.

Seguido a secagem, costuma ser feita a trituração e peneiração (LÓPEZVARGAS et al., 2013; SEIXAS et al., 2014; OLIVEIRA et al. 2016a). Essa última é importante pois a literatura reporta que o tamanho das partículas de farinha exerce forte influência na funcionalidade do produto. Logo, a obtenção de granulometria padronizada pode ser fundamental para características como textura, sabor e aparência e valor nutricional (AHMED et al., 2016; BOURRÉ et al., 2019; MARCHINI et al., 2021).

\section{B) CARACTERÍSTICAS QUÍMICAS E FISICO-QUÍMICAS DA PFP}

Após descritas algumas metodologias para elaboração de farinha PFP ou farinha de albedo, características químicas como teor de proteínas, cinzas, lipídios, fibras, atividade de água e carboidratos são exibidas na Tabela 1.

$\mathrm{Na}$ Tabela 1, observa-se que os maiores teores de proteína foram apresentados por Ferreira e Tarley (2021), Lima et al. (2016) e Souza et al. (2018). A semelhança observada é que todos os autores compraram as farinhas para avaliação, não apresentando a metodologia de preparo. Variações nas cultivares e nas metodologias de preparo podem exercer certa influência na resposta proteica. Além disso, os teores de proteína da farinha produzida apenas com albedo por López-Vargas et al. (2013) e Costa et al. (2021) que apresentaram 0,35\% e 0,87\% são significativamente menores que os encontrados nas farinhas de epicarpo e mesocarpo (CAZARIN et al., 2014; COELHO et al., 2017a; SOUZA et al., 2018).

Houve acréscimo nos teores de proteínas quando a parcela de epicarpo foi adicionada sendo, possivelmente, a responsável. Ning et al. (2020) observaram na farinha de epicarpo um teor de proteína um pouco maior dos que os apresentados 
na Tabela 1 para autores que avaliaram farinha de casca. Visto isso, existe a possibilidade de que as farinhas de mais alto teor proteico da Tabela 1, tenham sido produzidas por cultivares mais proteicas ou, simplesmente por frações com menores proporções de albedo.

$\mathrm{Na}$ Tabela 1, é possível encontrar teores de cinza de 2,34 a 8,08\%. Para empregar farinha de PFP em formulações, deve ser considerado que um alto teor de cinzas pode ser cautelosamente avaliado para a sua potencial aplicação como ingrediente em alimentos, uma vez que a alta quantidade de íons metálicos aumentaria consideravelmente a oxidação do produto (MARTINEZ et al., 2012).

Em seu trabalho, Nascimento et al. (2013) reportam a variação no teor de fibras do albedo de maracujá entre 35,03 e 90,32\%. Tais discrepâncias nos teores de fibra podem ser associados às metodologias seguidas nos trabalhos, já que as parcelas solúveis podem ser perdidas por lixiviação (COELHO et al., 2017a). A grande quantidade de fibras dietéticas solúveis promove a PFP a um ingrediente interessante para inclusão em vários alimentos devido a sua capacidade de retenção de água, que aumenta a satisfação pós-prandial.

TABELA 1. Propriedades químicas da farinha de casca de maracujá ou farinha de albedo*. Legenda: S. = Solúveis; In. = Insolúveis

\begin{tabular}{|c|c|c|c|c|c|c|}
\hline Referência & $\begin{array}{c}\text { Ferreira e Tarley } \\
2021\end{array}$ & $\begin{array}{c}\text { Coelho et al. } \\
2017 a\end{array}$ & $\begin{array}{c}\text { Cazarin et al. } \\
2014\end{array}$ & $\begin{array}{c}\text { Souza et al. } \\
2018\end{array}$ & $\begin{array}{l}\text { Lima et al. } \\
2015\end{array}$ & $\begin{array}{c}\text { López- } \\
\text { Vargas et al. } \\
2013^{*}\end{array}$ \\
\hline $\begin{array}{l}\text { Proteínas } \\
\text { (g/100g) }\end{array}$ & $7,15-8,41$ & $2,54-3,85$ & 3,94 & $7,2-8,5$ & 8,87 & 0,35 \\
\hline $\begin{array}{l}\text { Cinzas } \\
(\mathrm{g} / 100 \mathrm{~g})\end{array}$ & $2,34-4,44$ & $6,92-7,14$ & 6,88 & - & 6,00 & 8,08 \\
\hline $\begin{array}{l}\text { Fibras S. } \\
(\mathrm{g} / 100 \mathrm{~g})\end{array}$ & - & $16,98-22,00$ & 17,11 & - & 20,13 & 52,34 \\
\hline $\begin{array}{l}\text { Fibras In. } \\
(\mathrm{g} / 100 \mathrm{~g})\end{array}$ & - & $38,48-50,92$ & 42,12 & - & 39,96 & 19,45 \\
\hline $\begin{array}{l}\text { Fibras totais } \\
(\mathrm{g} / 100 \mathrm{~g})\end{array}$ & - & $61,32-50,92$ & 65,22 & - & 60,08 & 71,79 \\
\hline $\begin{array}{l}\text { Lipídeos } \\
\text { (g/100g) }\end{array}$ & $1,94-3,47$ & $0,69-0,85$ & 0,31 & - & 3,39 & 1,00 \\
\hline $\begin{array}{l}\text { Atividade de } \\
\text { água }\end{array}$ & - & $0,34-0,36$ & 0,43 & - & & 0,164 \\
\hline $\begin{array}{c}\text { Carboidratos } \\
(\mathrm{g} / 100 \mathrm{~g})\end{array}$ & - & - & 79,39 & $48,7-62,8$ & 14,24 & - \\
\hline
\end{tabular}

Fonte: Elaborado pelas autoras com dados dos autores da linha 1.

Em variação às metodologias que elaboram farinha, Dias et al. (2011) elaboraram polpa de albedo (albedo cozido + água). Observaram umidade de $96,48 \%$ pH de 4,06, acidez titulável 0,34, sólidos solúveis $2,00^{\circ}$ Brix, açúcar redutor e total com percentual em glicose 4,77 e 9,56, pectina total e solúvel em mg de ácido galacturônico por $100 \mathrm{~g}$ de polpa 24,15 e 0,13, respectivamente.

Quanto aos parâmetros de coloração das farinhas, adota-se "L" para Luminosidade, "b" para a coordenada amarelo-azul e "a" para a coordenada 
vermelho-verde. Conforme apresentando na Tabela 2, os autores (SILVA et al. 2016) observaram uma tendência de acréscimo na intensidade da coloração vermelha e tendência ao amarelo com o aumento da temperatura de secagem, o que pode justificar a discrepância na coloração de farinhas produzidas sob metodologias distintas. As cores das farinhas de PFP podem estar relacionadas a suas composições de monossacarídeos e os trabalhos de Coelho et al. (2017a) e de Seixas et al. (2014) fazem menção às suas composições.

TABELA 2. Parâmetros de coloração da farinha de PFP de acordo com o tratamento térmico utilizado para secagem.

\begin{tabular}{|c|c|c|c|c|}
\hline $\begin{array}{l}\text { Tratamento } \\
\text { térmico }\end{array}$ & $\mathrm{L}$ & $\bar{A}$ & $\mathrm{~B}$ & Referência \\
\hline Fervura & 35,98 & 0,66 & $-1,26$ & Dias et al. (2011) \\
\hline $50^{\circ} \mathrm{C}$ & 36,71 & 7,53 & 24,57 & $\begin{array}{l}\text { Coelho et al. } \\
\text { (2017b) }\end{array}$ \\
\hline $50^{\circ} \mathrm{C}$ & 83,99 & 1,82 & 20,08 & Silva et al. (2016) \\
\hline $60^{\circ} \mathrm{C}$ & 79,91 & 1,53 & 14,79 & $\begin{array}{l}\text { López- Vargas et } \\
\text { al. (2013) }\end{array}$ \\
\hline $60^{\circ} \mathrm{C}$ & 94,30 & 3,18 & 26,28 & Silva et al. (2016) \\
\hline $70^{\circ} \mathrm{C}$ & 94,50 & 3,63 & 26,76 & Silva et al. (2016) \\
\hline $80^{\circ} \mathrm{C}$ & 89,77 & 4,62 & 30,06 & Silva et al. (2016) \\
\hline
\end{tabular}

Fonte: Elaborado pelas autoras com dados dos autores citados na coluna 5.

\section{C) EXTRAÇÃO DE PECTINA DE PFP}

A casca do maracujá é uma fonte de pectina com rendimento de até $20 \%$ (LIEW et al., 2014). As pectinas são polissacarídeos complexos que consistem principalmente de unidades de ácido galacturônico sendo ligadas por ligações $\alpha$ $(1 \rightarrow 4)$. Ela é encontrada tanto na parede celular primária de suas células, quanto no ambiente extracelular, contribuindo para a adesão entre as células, firmeza e força do tecido (SEIXAS et al., 2014). A homogalacturonana (HG) é o mais abundante polissacarídeo péctico na parede celular, correspondente a cerca de $60-65 \%$ do total da pectina.

A Food and Agriculture Organization (FAO) determina que a pectina deve ser no mínimo constituída por $65 \%$ de ácido galacturônico (LIEW et al., 2014; SEIXAS et al., 2014). A outra fração principal é a ramnogalacturonana I, em que uma variedade de diferentes cadeias de glucanas (principalmente arabinana e galactana) está ligada às unidades de ramnose (CELUS et al., 2018).

A pectina é amplamente utilizada na indústria alimentícia, principalmente como agente gelificante no preparo de doces, geleias e confeitos (COELHO et al., 2017a). Seu grau de esterificação, DE (degree of esterification) é muito relevante para sua aplicação industrial. É definido como a proporção de unidades de ácido carboxílico esterificado perante a quantidade total de ácido carboxílico na pectina. Tem uma grande influência nas propriedades do gel da pectina. 
Principalmente para fins tecnológicos, ela pode ser classificada como de alto grau de esterificação (acima de 50\%) ou baixo grau (até $50 \%$ ) (LIEW et al., 2014). A pectina de alto $\mathrm{DE}$ forma géis com a presença de sacarídeos em $\mathrm{pH}$ por volta de 2,5 - 3,5. Por outro lado, a pectina de baixo DE é menos dependente do $\mathrm{pH}$ e dos sólidos solúveis. Sua gelificação é promovida pela presença do íon Cálcio II, que promove interações do tipo ácido-base de Lewis. Por isso, é comumente empregada na como espessante em produtos diet (HAN et al., 2017).

Nesse trabalho, alguns dos principais métodos recentes de extração serão apresentados nos tópicos seguintes.

\section{C.1) Extração convencional de pectina de PFP}

Após a produção da farinha, a extração da pectina se dá num processo físicoquímico de múltiplos estágios influenciados, principalmente, por fatores como tempo, temperatura e pH (OLIVEIRA et al., 2016a) e é a etapa mais importante da produção industrial de pectina. O Fluxograma apresentado na Figura 1, sintetiza as etapas.

A separação é influenciada principalmente por fatores como tempo, temperatura e pH (SEIXAS et al., 2014). De forma convencional, a extração é realizada em meio ácido ou alcalino. Para extração industrial, geralmente usam-se os meios ácidos, que causam menor grau de despolimerização e alto DE. $\mathrm{Na}$ extração, geralmente, são utilizados fortes ácidos minerais como o fosfórico, nítrico e hidroclórico que podem causar corrosão nos equipamentos e dificuldades de eliminação de resíduos (LIEW et al., 2014).

Após esta etapa, realiza-se a purificação do extrato por meio de filtração ou centrifugação. Em seguida, usam-se soluções alcoólicas para induzir a precipitação do polímero. Uma sequência de lavagens também alcoólicas é feita para remover as impurezas solúveis, até a obtenção de um produto purificado.

FIGURA 1. Fluxograma da extração convencional de pectina.

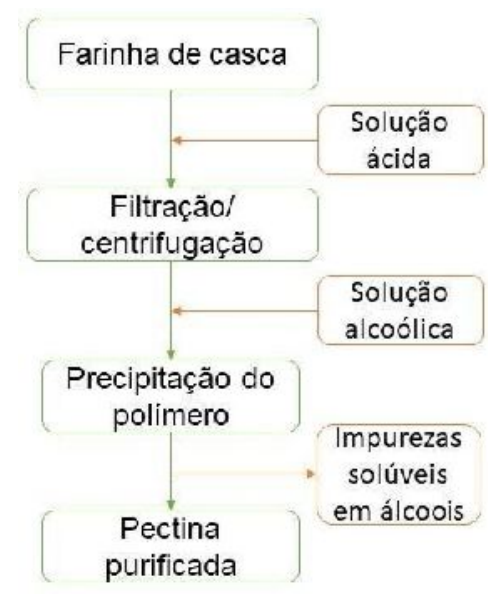

Fonte: As autoras (2021)

\section{C.2) Extração de pectina de PFP assistida pelo uso de ácidos orgânicos}

O método tradicional utiliza solventes minerais nocivos à saúde e ao meio ambiente. Assim, recentemente, tem se buscado fazer a extração com ácidos orgânicos não tóxicos, como ácido cítrico e acético (LIEW et al., 2014; SEIXAS et al., 2014). 
Liew et al. (2014) avaliaram a eficiência de extração da pectina com ácido cítrico em diferentes pHs e tempos. Foi observado que a eficiência de extração aumentou com o acréscimo de tempo, que foi justificada pela interação do ácido com o substrato. Após o pico em 75min, o rendimento da extração passou a diminuir e supôs-se que maiores tempos de submissão tenham causado hidrólise de ligações éster e glicosídicas. Isso explica o decréscimo no DE que também foi observado.

Os autores (LIEW et al., 2014) consideraram que o pH foi o parâmetro mais importante na influência da extração. A máxima extração $(14,6 \%)$ foi no menor $\mathrm{pH}$, auxiliada pelos íons hidrônio que estimulam a hidrólise de protopectina. Os grupos carboxilatos são convertidos em ácido carboxílico, o que aumenta a intensidade das interações químicas promovendo a precipitação a baixos $\mathrm{pH}$. No entanto, foi observada baixa influência no grau de esterificação.

Seixas et al. (2014) com argumentos similares, propuseram o uso dos ácidos cítrico, tartárico e nítrico em combinação com o uso de micro-ondas para minimizar esses efeitos adversos da extração de pectina de PFP. Também foi feita a relação com a massa molar dos compostos encontrados e o extrato tratado com ácido tartárico apresentou os menores valores, ficando por volta de $2.298 \times 10^{5} \mathrm{~g} / \mathrm{mol}$, menos que a metade do apresentado para os outros dois ácidos.

Seixas et al. (2014) observaram interferência do tipo de ácido no DE, que ficou em torno de $50 \%$ para ácido tartárico, ao passo que os outros dois apresentaram resultados maiores que $64 \%$. Isso se deve ao fato de o ácido tartárico possuir dois grupos carboxílicos terminais, portanto, seu poder hidrolítico é maior do que o do ácido acético que possui apenas um grupo carboxílico terminal. Logo, apesar do uso do ácido tartárico proporcionar maiores rendimentos, ele degradou a pectina extraída.

\section{C.3) Extração de pectina assistida por microondas.}

Com o objetivo de requerer menores quantidades de solvente e de energia, reduzindo o impacto ecológico, Seixas et al. (2014) foram os primeiros a investigar a extração de pectina de PFP assistida por microondas. Consideraram as vantagens de fazer uso de pressão atmosférica em relação a vasos pressurizados, pois o método utiliza baixas temperaturas em relação a sistemas de vaso fechado; o equipamento necessário possui menor custo; a ausência de qualquer necessidade de resfriamento ou despressurização; a capacidade de adicionar reagentes a qualquer momento durante o tratamento, além de ser mais adequada para a presença de termolábeis (SEIXAS et al., 2014; CHATURVEDI, 2018). O método é considerado seguro, necessita de menos espaço que métodos convencionais e quantidades reduzidas de solvente (FREITAS et al., 2020).

Dentre os ácidos estudados por Seixas et al. (2014), o tartárico apresentou maior percentual de extração, quando comparado ao acético e nítrico sendo, em alguns casos, mais que o dobro. A extração feita com ácido acético foi afetada apenas pelo tempo, e a variação de potência do equipamento mostrou pequena relevância. Por isso, pôde ser realizada com a menor potência sem danos no rendimento. No entanto, embora a extração com ácido tartárico tenha sido alta, a massa molar dos extratos era baixa assim como o conteúdo de ácido urônico, enquanto o ácido acético apresentou o comportamento oposto. Logo, foi sugerida a realização de outros estudos para esclarecimento da ação de cada ácido no substrato.

Além disso, foi observado um acréscimo de rendimento quando realizada a extração com uso de microondas, que pode ser devido a conversão do campo 
eletromagnético em calor. Os vapores formados são capazes de romper os capilares vegetais, liberando as substâncias pécticas. Foi observado que o uso de microondas aumenta a eficiência do processo, principalmente requerendo menos energia e tempo para a extração.

Embora o trabalho de Seixas et al. (2014) tenha sido o primeiro a utilizar o método para extração de pectina maracujá, outros trabalhos podem ser encontrados com métodos similares para outras frutas, principalmente cítricas com rendimentos satisfatórios (HOSSEINI, et al., 2016; GARCIA-GARCIA et al., 2019; DAO et al., 2021).

\section{C.4) Extração de pectina de PFP assistida por ultrassom}

A técnica de ultrassom utiliza energia acústica para criar ondas sonoras. Essas ondas passam por um meio expandindo e comprimindo, o que promove a cavitação (produção, crescimento e colapso de bolhas) (FREITAS et al., 2020). A cavitação promove a ruptura da parede celular, o que facilita a interação entre o solvente e o conteúdo da célula vegetal. A técnica é considerada uma técnica "verde e limpa". Por isso, a tecnologia de ultrassom tem sido muito utilizada para extrair uma ampla gama de compostos alimentares, como pigmentos, aromas, antioxidantes e outros compostos orgânicos e compostos minerais de diferentes matrizes (CHEMAT et al., 2017).

Souza et al. (2017) extraíram compostos flavonoides de casca de maracujá e do material que sobrou da extração, foi extraída a pectina. O método deles comparou dois solventes diferentes, metanol e etanol, e três métodos, o convencional, assistido por alta pressão e ultrassom. Segundo os autores, o rendimento de pectina não foi afetado pela extração prévia de flavonoides. No entanto, houve uma queda no valor, quando comparada ao método convencional.

Os parâmetros adotados para essa técnica no trabalho de Oliveira et al. (2016b) foram de entre 132,8 e $664,0 \mathrm{~W} / \mathrm{cm}^{2}$ de potência e frequência de $20 \mathrm{kHz}$. A temperatura foi variada de 45 a $85^{\circ} \mathrm{C}$ e o tempo extração de $10 \mathrm{~min}$, escolhido por análise prévia. Todos os ensaios obtiveram valores de DE maiores que $65 \%$. $O$ maior DE obtido, de $76,29 \%$, foi com a menor temperatura testada $45^{\circ} \mathrm{C}$ e potência de $132,8 \mathrm{~W} / \mathrm{cm}^{2}$

Foi percebido que a combinação de altas temperaturas e altas potências foi essencial para a eficiência de extração. Quanto ao DE, corroborando com outros estudos (LIEW et al., 2014; OLIVEIRA et al., 2016a), houve uma queda com o acréscimo de temperatura. O mesmo não foi observado para intensidade da potência, que não exerceu influência no DE. Os resultados foram considerados satisfatórios pois, quando comparados com os da extração convencional, apresentaram 1,6 vez mais rendimento, além de necessitar de 66\% menos tempo.

Existem também estudos na literatura que abordam a possibilidade de uso simultâneo de ultrassom e microondas para extração de compostos, mostrando resultados satisfatórios (SILLERO et al., 2020). No entanto, até a escrita desse trabalho não foi encontrado nenhum estudo para extração de pectina de casca de maracujá utilizando estes métodos simultaneamente.

\section{C.5) Extração de pectina de casca assistida por altas pressões}

A técnica convencional de extração exige muito tempo e energia, além de causar degradação térmica da fibra, com temperaturas de 60 a $100^{\circ} \mathrm{C}$ de 20 a 360min (OLIVEIRA et al., 2016a). Por isso, tem-se desenvolvido interesse em fazer combinações com técnicas não convencionais para otimizar a extração tanto 
energeticamente, quanto em rendimento e qualidade. Devido a alguns aspectos negativos sobre a extração convencional de pectina, alguns estudos têm sido desenvolvidos com a técnica de HPP (high pressure processing) que vem sendo aplicada para extração de ingredientes ativos em vegetais (ALEXANDRE et al., 2017a; ALEXANDRE et al., 2017b; WEN et al., 2018). Essa técnica geralmente conta com variações de pressão entre 100 e $600 \mathrm{MPa}$, as temperaturas de 10 a 50 ${ }^{\circ} \mathrm{C}$, e o tempo de extração, de 5 a 30min (FREITAS et al., 2020).

OLIVEIRA et al. (2016a) utilizaram a técnica de HPP, para extração de pectina de casca de maracujá e avaliaram a eficiência da técnica. Os autores propuseram que extrações a temperaturas menores evitam a degradação térmica e modificam a estrutura da parede celular, facilitam a permeabilidade, o que aumenta a interação com o solvente. A eficiência de extração foi avaliada sob a influência da pressão $x$ tempo; e a influência da pressão x temperatura. Foi observado que a extração aumentou a pressões moderadas e temperaturas por volta de $35^{\circ} \mathrm{C}$, o que não se manteve com o uso de pressões mais elevadas, por volta de $400 \mathrm{MPa}$. Considerouse que HPP como pré-tratamento aumenta a eficácia da extração mantendo bons níveis de $\mathrm{DE}$ e diminui o tempo necessário, quando comparado ao método tradicional.

\section{C.6) Extração enzimática de pectina de casca de maracujá}

A extração enzimática de pectina tem sido investigada em diversos trabalhos principalmente por causa do alto rendimento proporcionado, boa qualidade do extrato e considerável economia de energia. São utilizados diferentes tipos de enzimas de diversas fontes, sendo comumente citadas as celulases a $\alpha$-amilases (JEONG et al. 2014; SUN et al., 2015; WIKIERA et al., 2016; NADAR et al., 2018; DRANCA et al., 2020). A extração enzimática evita que o ácido galacturônico seja degradado ou derivatizado pelas condições convencionais de extração, demonstrando pontos positivos para sua aplicação (VASCO-CORRÊA; ZAPATA 2017).

Vasco-Corrêa e Zapata (2017) investigaram a técnica em casca de maracujá amarelo e descreveram rendimentos de 17,0 a $25,8 \mathrm{~g} / 100 \mathrm{~g}$ de casca, que foram $40 \%$ maiores do que o rendimento da extração química. Sua condição ótima de extração foi atingida com $30 \mathrm{U} / \mathrm{mL}$ de protopectinase-SE a $37^{\circ} \mathrm{C}$ e $\mathrm{pH}$ de 3,0 , parâmetros que exerceram forte influência no rendimento. O tempo necessário para obter o máximo rendimento foi de $2 \mathrm{~h}$, consideravelmente maior do que o apresentado em outras metodologias citadas neste trabalho.

Liew et al. (2015) utilizaram Celluclast, um preparo enzimático que catalisa a lise dos polímeros de glicose formadores da celulose, para conduzir sua extração. Seu rendimento variou de 2,59 a 9,17\% e seu maior valor foi superior ao obtido por extração ácida conduzida comparativamente pelos autores. O DE variou de 52,63 a $86,96 \%$. Com base nos resultados, menores concentrações enzimáticas mostraramse mais eficientes para o processo, corroborando com os resultados de Donaghy e McKay's (1994). Além de acrescer substancialmente os custos operacionais, a enzima extra que permanece livre no meio reacional pode degradar a pectina solubilizada, e reduzir a eficiência do processo (VASCO-CORRÊA; ZAPATA, 2017).

\section{D) PROPRIEDADES TECNOLÓGICAS DA PFP}

A casca do maracujá tem sido reportada literatura como potencial fonte de fibras, como pode ser visto na tabela 1, apresentada anteriormente. Com base nisso, López- Vargas et al. (2013) quantificaram a capacidade de retenção de água (soma 
da água ligada, da água hidrodinâmica e da água fisicamente retida) de sua farinha de albedo e obtiveram o resultado de $13,00 \mathrm{~g}$ de água por $\mathrm{g}$ de amostra, ao passo que Weng et al. (2021) encontraram 8,10 e 8,30 para farinha de PFP amarelo e roxo, respectivamente. Observaram que a farinha de albedo além de promover o desenvolvimento de viscosidade e preservação de frescor, tem aplicações potenciais em produtos que requerem hidratação, tornando-se potencial ingrediente para alimentos assados ou produtos de carne cozida.

O parâmetro de retenção de lipídios ajuda a correlacionar a capacidade de retenção dos componentes do sabor. Os resultados de Weng et al. (2021) quantificaram de 2,38 a 2,44, ficando próximo do resultado de López-Vargas et al. (2013) com 2,03, que implicam que possivelmente, a adição de farinha de casca de maracujá pode agregar informações de flavores ao alimento.

Além do interesse no teor de fibras, a presença de compostos fenólicos tem sido vastamente estudada. Cao et al. (2021) correlacionam a capacidade antioxidante do extrato de casca de maracujá com o conteúdo de polifenóis e flavonoides. Vários autores (LÓPEZ-VARGAS et al., 2013; TOHIDI et al., 2017; MAZZA et al., 2018; LIU et al., 2019) sugerem que a maior parte da atividade antioxidante é devida a presença de flavonoides, isoflavonas, flavonas, antocianinas, catequinas, e outros compostos fenólicos e polifenólicos.

Os compostos supracitados têm atividade antioxidante, induzem o efeito quelato em íons metálicos, inativando cadeias de radicais livres de lipídios e prevenindo a conversão de hidroperóxidos em oxirradicais reativos. Ainda assim, a atividade antioxidante total pode ser potencializada com a presença de outros constituintes, tais como ascorbatos, carboidratos redutores, tocoferóis, carotenoides, terpenos e pigmentos (LÓPEZ-VARGAS et al., 2013).

A composição fenólica da PFP também tem sido estudada. Nascimento et al. (2016) perceberam uma queda no teor de ácido gálico total durante o processo de secagem, que foi de $381,3 \mathrm{mg} / 100 \mathrm{~g}$ na casca fresca ao mínimo de $143,8 \mathrm{mg} / 100 \mathrm{~g}$ na casca seca. López-Vargas et al. (2013) através de HPLC (high performance liquid chromatography) identificaram dois compostos glicosilflavonas $\mathrm{C}$ como principais: isoorientina e isovitexina, que corrobora com os resultados de Viganó et al. (2016).

Outros autores também avaliaram teor de compostos fenólicos em maracujá e obtiveram consideráveis variações nos resultados que podem ser atribuídas às variações naturais de cada fruto, as partes analisadas (cascas, sementes, polpa) ou as metodologias utilizadas (OLIVEIRA et al., 2009; LAZZARI et al., 2021).

López-Vargas et al. (2013) combinaram mais de um método in vitro para avaliação da capacidade antioxidante de farinha de albedo e observaram que para todos os solventes analisados, houve um considerável aumento na atividade de eliminação de radicais à medida que a concentração de albedo em pó foi aumentada.

O extrato de casca de maracujá também tem sido estudado para fins de atividade antimicrobiana. Ramli et al. (2020) observaram o comportamento de quatro culturas de bactérias. Os resultados de inibição mostraram-se satisfatórios para $E$. coli, S. marcescens, e S.aureus e não apresentou inibição no crescimento de $P$. vulgaris, que são patógenos comuns em alimentos refrigerados.

Nugraha et al. $(2018 ; 2019)$ encontraram flavonóides, taninos, saponinas e esteróides na casa de maracujá roxo, fitoquímicos com propriedades antibacterianas e antivirais que foram correlacionados a inibição de $S$. aureus e E. coli. A farinha de albedo do maracujá amarelo apresentou ação inibitória superior ao crescimento de 
diversas bactérias ( $L$. innocua, $A$. hydrophila, $A$. denitrificans, $A$. faecalis $E$. amnigenus, E. gergoviae, $S$. marcescens, $S$. putrefaciens, $P$. fragi, $P$. fluorescens) quando comparada a farinha de sementes e polpa. No entanto, as bactérias apresentaram maior resistência aos compostos da casca do que à nisina, que foi reportada como único bactericida aceito como conservante natural em alimentos (LÓPEZ-VARGAS et al., 2013).

\section{E) APLICAÇÕES TERAPÊUTICAS DA PFP}

Várias espécies do gênero Passiflora são amplamente utilizadas na medicina tradicional em muitos países. No Brasil, o maracujá é conhecido popularmente pela sua ação calmante (OLIVEIRA et al., 2019). Lewis et al. (2013) investigaram a ação do extrato de casca no controle de pressão arterial de ratos e observaram que a partir de $50 \mathrm{mg} / \mathrm{kg}$ de peso corporal, já havia diferença significativa no controle. A ação foi atribuída principalmente ao ácido edúlico e a fração de antocianinas. Corroborando com seus resultados, outros estudos in vivo com extrato de maracujá amarelo e roxo também apresentaram ação anti-hipertensiva (ICHIMURA et al., 2006; ZIBADI et al., 2007).

A casca como subproduto do processamento de maracujá tem despertado atenção de pesquisas com fins terapêuticos devido a alguns aspectos como seu alto teor de fibras, sua capacidade antioxidante, conteúdo mineral e de vitamina B3 (SILVA et al., 2016 ; BORDIM et al., 2018). O alto conteúdo de fibra dietética solúvel encontrada na casca a torna um ingrediente interessante para inclusão em vários alimentos devido à afinidade química entre a fibra e a água, que formam géis viscosos e aumentam a sensação de saciedade (GALISTEO et al., 2008; SILVA et al., 2016).

Adi (2020) investigou o efeito do suco de casca de maracujá amarelo na proporção das proteínas LDL (low-density lipoprotein) e HDL (High-density lipoprotein) em pacientes com diabetes mellitus tipo 2, e observou a influência positiva no controle de colesterol corroborando com outros autores (CORRÊA et al., 2014; de SOUSA et al., 2020; GOMES et al., 2021).

A farinha de casca de maracujá demonstrou função como um ingrediente dietético e contribuiu para o equilíbrio nos índices glicosídicos. Em seu trabalho, Lima et al. (2016) evidenciam que a casca de maracujá pode ser um componente alimentar útil para prevenir a gordura corporal e a resistência à insulina. Além disso, estudos epidemiológicos sugeriram que dietas ricas em fibras dietéticas solúveis podem proteger contra fatores de risco de doenças cardiovasculares (MARQUES et al., 2017).

A pectina obtida da casca é uma fibra solúvel considerada potencial auxiliar no controle de distúrbios metabólicos (resistência à insulina, obesidade, distúrbio da homeostase da glicose, hipertensão arterial, triglicerídeos séricos elevados e baixo HDL) (SILVA et al., 2011; SOUSA et al., 2020; ADI, 2020). Silva et al. (2011) sugerem que a pectina pode influenciar positivamente no controle dos níveis de aminotransferases hepáticas, que se muito elevados podem ser marcadores de doenças hepáticas. Em trabalhos com diabéticos, a casca de maracujá tem mostrado importante ação hipoglicêmica e antiinflamatória, observada com a redução de liberação de mieloperoxidases (SILVA et al., 2011; LIMA et al., 2016).

Como escrito anteriormente, a riqueza em minerais da PFP tem sido investigada. Os minerais são essenciais para o bom funcionamento do metabolismo. Alguns estudos se dedicaram a correlacionar a sua presença com determinadas respostas do organismo. A exemplo, Zinco e Cobre são minerais importantes no 
sistema de defesa antioxidante, pois são cofatores importantes de enzimas (ROUT et al., 2016; MARREIRO et al., 2017).

Além disso, o Zinco foi relatado como necessário para a produção e armazenamento de insulina. Pode induzir um aumento no transporte de glicose para as células, potencializar o transporte de glicose induzido pela insulina e associado à prevenção de síndrome metabólica (MIAO et al., 2013). Os transportadores de Zinco também desempenham um papel significativo na patogênese do diabetes. $O$ conteúdo mineral também é responsável por regular a pressão osmótica, auxiliam no transporte entre membranas e fazem parte da constituição de tecidos biológicos (KRÓL et al., 2018).

Com base nessa discussão, Novaes et al. (2017) desenvolveram uma metodologia para avaliar a composição dos minerais Cálcio [Ca (II)], íons Cobalto [Co (II)], Cobre [Cu (II)], Ferro [Fe (III)], Potássio [K (I)], Magnésio [Mg (I)], Manganês [Mn (II)], Sódio [Na (I)] e Zinco [Zn (II)] em diferentes tecidos de maracujá. Foram identificados em quantidades maiores os íons Fe (III), Na (I) e Zn (II), e presença marcante de $\mathrm{Ca}$ (II) e K (I). Ferreira e Tarley (2021) avaliaram a composição mineral e bioacessibilidade da farinha de PFP e encontraram os compostos $\mathrm{Mn}$ em maior concentração e bioacessibilidade com 52\%, seguido de Mg (14\%) e Fe (12\%), após a digestão gastrointestinal.

Com base nos dados obtidos e de acordo com a Agência Nacional de Vigilância Sanitária do Brasil através da Portaria n² 27/1998 (ANVISA, 1998), considerando a ingestão de $100 \mathrm{~g}$ de farinha por dia, bem como a concentração biodisponível dos minerais, a farinha pôde ser classificada como "fonte" de Zn e Cu e, com "alto teor" de Mg, Mn e Fe (FERREIRA; TARLEY, 2021). Novaes et al. (2017) ainda afirmaram que a composição química do solo de cultivo, bem como a composição dos fertilizantes utilizados podem influenciar na composição de minerais dos frutos.

\section{F) APLICAÇÕES TECNOLÓGICAS DA PFP}

As farinhas de cereais e frutas têm grande versatilidade de uso e podem ser utilizadas em potencial para novos produtos alimentícios como o caso de panificação e confeitaria (SILVA et al., 2016). Ela pode ser aplicada de forma simples, para agregar seu valor, ou com interesse pelas suas propriedades tecnológicas. A procura por alimentos que forneçam benefícios à saúde permite 0 desenvolvimento de pesquisas relacionadas a alternativas que amenizem os sintomas e/ou consequências relacionadas a diversas patologias (BAZZANO et al., 2017).

Como a casca de maracujá é uma fonte de polissacarídeos, principalmente pectina, Bezerra et al. (2019) utilizaram pectina extraída do albedo do maracujá amarelo para realizar encapsulamento através de nanodispersão de carotenóides extraídos da microalga Spirulina sp.

A nanoencapsulação de carotenóides tem sido uma alternativa comumente buscada para aumentar a estabilidade desses compostos e as possibilidades de sua aplicação. No trabalho supracitado, a pectina de albedo de maracujá foi utilizada como uma proposta mais ecológica, perante ao uso comum de surfactantes tóxicos e polímeros sintéticos. A eficiência de encapsulação em todos os ensaios com pectina do albedo foi superior a 95\%. Foi observado melhor encapsulamento para carotenóides naturais quando comparados aos sintéticos. O tamanho das partículas dispersas foi considerado tão satisfatório e uniforme quanto os de ensaios feitos com polímeros sintéticos durante os 60 dias de estudo (BEZERRA et al., 2019). 
Com a discussão sobre redução do uso de polímeros sintéticos e necessidade de desenvolvimento de materiais biodegradáveis, Nascimento et al. (2012) utilizaram albedo de maracujá para elaboração de filmes flexíveis. Em comparação com os filmes de amido, mostraram-se mais resistentes e menos flexíveis. Reportou-se que foi possível elaborar filmes com mesocarpo com propriedades similares aos de amido de mandioca e foi recomendada a realização de mais estudos para otimização das propriedades e possíveis aplicações.

O documento "Diet, Nutrition and the Prevention of Chronic Diseases" da Organização Mundial da Saúde e FAO (WHO; FAO, 2002) recomenda o consumo acima de $25 \mathrm{~g}$ de fibras totais por dia. Elas, além de poderem ser aplicadas como ingredientes funcionais, têm propriedades comparáveis aos aditivos alimentares, atuando como espessantes ou gelificantes e estabilizadores de emulsões e espumas. Tais funções foram observadas na farinha de PFP, que tem alta quantidade de fibras, apresentando resultados satisfatórios quando aplicada em néctar e xarope de maracujá e maionese (COELHO et al., 2017b). Além disso, podem atuar como substitutos de gordura, tem capacidade de dilatação e podem aumentar a retenção de água, propriedades essenciais para o preparo de cremes, doces e sobremesas congeladas, entre outros produtos alimentícios (SOUZA et al., 2019a; KARACA et al., 2019).

Com base nas diversas propriedades aqui discorridas, Weng et al. (2021) produziram e caracterizaram biscoitos com adição de farinha de casca de maracujá. Foi percebido que grandes quantidades de um ingrediente com alta capacidade de retenção de água afeta negativamente a umidade durante o processo de cozimento. No entanto, a adição em quantidade apropriada reduz a umidade do produto possibilitando um acréscimo no shelf life.

A análise reológica mostrou que há um acréscimo na dureza em proporções a partir de $10 \%$ de farinha de PFP, que não seria favorável em uma aplicação industrial. De forma geral, os melhores resultados de análise sensorial foram para a formulação com $5 \%$ de farinha de PFP. A adição dessa fonte de fibras provocou uma significativa redução na atividade de água em relação à formulação controle (WENG et al., 2021).

Seguindo a mesma linha de produtos de confeitaria, a farinha de albedo do maracujá também foi utilizada como ingrediente de bolo com propriedades funcionais (OLIVEIRA et al., 2016b). Os autores ressaltaram a importância das fibras e sua relação com o teor de umidade do produto, que não pode ficar ressecado e nem muito úmido. Pôde-se observar que a adição de farinha de albedo não interferiu substancialmente no teor de proteínas e gorduras, aumentou o teor de cinzas e mais que triplicou o teor de fibras em relação à formulação controle.

Oliveira et al. (2016b) também avaliaram os atributos sensoriais com escala de 1 (desgostei extremamente) a 7 (gostei extremamente). O produto adicionado de apenas de farinha de albedo ficou por volta de 4,7 enquanto o controle, 5,7. Isso demonstra a necessidade de realização de testes para diminuir a discrepância de aceitabilidade sensorial entre fórmula funcional e o controle.

Um dos desafios que as indústrias enfrentam ao aumentar o teor de fibra dietética e grãos integrais nos alimentos é a mudança na cor e na textura, e em outras propriedades físico-químicas que esses ingredientes funcionais podem produzir. Nos trabalhos citados neste tópico, foi possível observar que os melhores resultados em aceitação da análise sensorial foram obtidos com teores mais baixos de farinha de albedo/casca adicionada. 
Ainda nos produtos com base de farinha de trigo, Fogagnoli e Seravalli (2014) desenvolveram uma massa alimentícia enriquecida com farinha de casca de maracujá para elevação do teor de fibras. Com base em análise estatística, observaram que o teor de $5 \%$ era mais adequado que a adição de $8 \%$ quando foram avaliadas questões como perda de sólidos e elasticidade da massa. Com a proporção de $5 \%$, não foi reportada diferença significativa entre a formulação enriquecida e o controle. Assim, sua massa alimentícia pôde ser caracterizada como fonte de fibras, segundo os parâmetros estabelecidos na Resolução RDC № 54, de 12 de novembro de 2012, que determina o mínimo de $2,5 \mathrm{~g}$ em porção de $80 \mathrm{~g}$ (ANVISA, 2012).

Outra possibilidade de aplicação observada foi como ingrediente de barras de cereais, que são uma alternativa pouco perecível, de consumo prático e saudável com carboidratos, vitaminas e minerais. Bordim et al. (2018) prepararam barras que continham aveia, flocos de arroz, coco ralado, açúcar cristal e mascavo, mel, óleo vegetal, Farinha de albedo (6, 3 e 9\%), Farinha de carambola (6, 9 e 3\%), Suco de carambola $(2,5,3,75$, e $1,25 \%)$ e suco de maracujá $(2,5,1,25$, e $3,75 \%)$. Na análise sensorial, as barras preferidas costumavam ser as que tinham a proporção 1:1 de farinhas ou as que tinham maior percentual de carambola. Os altos teores de albedo e suco de maracujá não foram bem aceitos sensorialmente.

Além dessas possibilidades, na literatura encontram-se massas com e sem glúten, em que geralmente a farinha de casca de maracujá aumenta o teor de fibras, cinzas e pode reduzir a o valor energético (RIBEIRO et al., 2018; GARCIA et al., 2019). Adicionalmente, outras formulações de biscoitos (GARCIA et al., 2019; SOUZA et al., 2019b), geléia (SOUZA et al., 2016; COSTA et al., 2021), hambúrguer (SANTOS et al., 2021), pão (CONTI-SILVA et al., 2015; CONSTANTINO et al., 2018), iogurte funcional (PERINA et al., 2015); doce com casca (DIAS et al., 2011) podem ser encontradas na literatura.

\section{F.1) Presença de compostos cianogênicos na PFP}

A casca do maracujá possui glicosídeos cianogênicos (BISWAS et al. 2021) que têm função natural de defesa da planta. Quando o tecido vegetal é rompido, uma reação enzimática que transforma os glicosídeos até ácido cianídrico é desencadeada (NASCIMENTO et al., 2013). Em passiflora edulis, reportou-se que o teor de cianogênicos é reduzido com o amadurecimento do fruto e cai para um nível subtóxico após a abscisão (SPENCER; SEIGLER, 1983). Na elaboração desse trabalho, não foi encontrada uma vasta gama de trabalhos científicos que consideram a presença desses compostos.

O cianeto é altamente tóxico, pois através da interação com a enzima Citocromo Oxidase, atua inibindo a liberação de oxigênio das moléculas de hemoglobina no sangue, o que interrompe o processo de respiração celular e leva à morte celular rápida por asfixia (AL-BEIRUTY et al., 2020). A toxicidade do cianeto pode ocorrer em animais, incluindo humanos, em doses entre 0,5 e 3,5 mg de HCN por quilograma de peso corporal, o que coloca crianças e pessoas menores em condição de maior vulnerabilidade. Os sintomas de toxicidade por cianeto em humanos incluem vômito, dor de estômago, diarréia, convulsão e, em casos graves, morte.

Devido a toxicidade desses compostos, alguns autores se dedicaram a caracterizá-los em maracujá. A prunasina foi considerada o glicosídeo cianogênico mais importante na casca, embora com algumas variações nos teores reportados. Chassagne et al. (1996) encontraram $286,9 \mathrm{mg} / \mathrm{kg}$ de casca de maracujá amarelo 
enquanto Spencer e Seigler (1983) apresentaram percentuais de acordo com o estádio de maturação e cultivar da fruta que variaram de 0,07 a $0,65 \%$. Outros compostos como linamarina, amigdalina e mandelonitrila-ramnosídeo também foram reportados (CHASSAGNE et al., 1996).

Alguns produtos alimentícios da Nova Zelândia foram avaliados por Cressey et al. (2013). Entre eles, maracujá e produtos com maracujá como ingrediente. Apenas na fruta foram encontrados níveis de ácido cianídrico acima do limite de detecção. No caso do maracujá como ingrediente, o teor caiu para abaixo do limite do método utilizado.

Como já visto até aqui, há vários estudos sobre aplicações para a PFP. No entanto, a quantidade de dados na literatura a respeito da toxicologia desse subproduto ainda é escassa. O trabalho de Nascimento et al. (2013) chamam atenção para a necessidade de investigação do tema para garantir o uso inócuo da PFP.

O trabalho de revisão de He et al. (2020) faz uma abordagem do ponto de vista fitoquímico e farmacológico da Passiflora Edulis. Os autores fazem menção sobre compostos glicosídeos cianogênicos e em seu trabalho não há relatos de toxicidade causada pelo fruto. No entanto, ficou sugerida a realização de mais estudos para comprovar a segurança toxicológica em animais e humanos.

Anuranji e Shamina (2018) não observaram sinais de toxicidade em ratos que consumiram até $550 \mathrm{mg} / \mathrm{kg}$ de peso corporal de extrato etanólico de PFP durante 90 dias. De maneira similar, Alves et al. (2020) administraram doses máximas de $2000 \mathrm{mg} / \mathrm{kg}$ de extrato de maracujá a ratos por 14 dias e também não observaram toxicidade.

O estudo conduzido por Medeiros et al. (2009) avaliou pacientes saudáveis que consumiram PFP durante oito semanas. Não houve relato de reações adversas que pudessem comprometer seu uso, além de não terem sido evidenciados sinais de toxicidade.

Embora existam compostos cianogênicos na casca do maracujá, Vernaza et al. (2009) optaram por utilizá-la como fonte de fibras para preparo de cereal orgânico. Os autores destacaram a necessidade de não negligenciar o teor de compostos cianogênicos e avaliaram a eficiência do processo de extrusão termoplástica para redução desses compostos. Como resultado, de acordo com a metodologia estudada, houve apenas uma pequena redução no conteúdo total.

Devido a necessidade de manutenção da segurança alimentar, alguns documentos elaborados pela OMS e FAO oferecem às autoridades nacionais e locais, fabricantes e outros órgãos relevantes orientações sobre como produzir produtos com concentrações seguras de compostos cianogênicos residuais (WHO; FAO, 2011; 2013). Além disso, outras metodologias que fazem a combinação de calor, força mecânica, pressão e teor de umidade possibilitam uma queda nos índices de compostos antinutricionais preservando a qualidade nutricional do alimento (NASCIMENTO et al., 2013).

\section{CONSIDERAÇÕES FINAIS}

Com base no que foi apresentado, observou-se que para ser aproveitada, a PFP em grande parte das vezes é transformada em farinha. A PFP apresenta um alto teor de fibras e seu teor de proteínas pode variar bastante. Uma das suas principais aplicações é como fonte de pectina. Existem diversas metodologias que podem ser utilizadas para extração de pectina da casca, obtendo qualidade comparável com a cítrica industrial. O seu potencial na elaboração de produtos 
alimentícios com objetivo nutricional ou/e tecnológico tem sido investigado e tem se percebido uma queda na aceitação sensorial de produtos com muita adição de PFP. O maracujá tem glicosídeos cianogênicos em sua composição, mas apesar disso, não tem demonstrado toxicidade nos estudos realizados. Os resultados desse trabalho sugerem que a PFP tem sido estudada majoritariamente para aplicações tecnológicas que visam seu alto teor de fibras, como elaboração de filmes, material para encapsulação, como ingrediente alimentício funcional.

\section{AGRADECIMENTOS}

As autoras agradecem ao Conselho Nacional de Desenvolvimento Científico e Tecnológico (CNPq) pelo suporte financeiro.

\section{REFERÊNCIAS}

ADI, D.I. The effect yellow passion fruit peel juice (Passiflora eduils f.flavicarpa deg) on LDL to HDL cholesterol ratio in type 2 diabetes mellitus patients as predictors of cardiovascular disease. Jurnal Gizi Dan Dietetik Indonesia (Indonesian Journal Of Nutrition And Dietetics), v. 8, n. 2, p. 61, 1 fev. 2020. Disponível em: <http://dx.doi.org/10.21927/ijnd.2020.8(2).61-67>. DOI: 10.21927/ijnd.2020.8(2).6167

AHMED, J.; TAHER, A.; MULLA, M. Z.; AL-HAZZA, A.; LUCIANO, G. Effect of sieve particle size on functional, thermal, rheological and pasting properties of Indian and Turkish lentil flour. Journal Of Food Engineering, v. 186, p. 34-41, out. 2016. Disponível em: http://dx.doi.org/10.1016/j.jfoodeng.2016.04.008. DOI: 10.1016/j.jfoodeng.2016.04.008

AL-BEIRUTY, R. Z; CHEYED, S. H.; HASHIM, M. H. Hazards of toxic hydrocyanic acid (hcn) in sorghum and ways to control it : a review. Plant Archives, v. 20, n. 01, p. 2726-2731, 2020. Disponível em: <http://www.plantarchives.org/SPECIAL\%20ISSUE\%2020-1/164_2726-2731_.pdf>.

ALEXANDRE, E. M. C.; ARAÚJO, P.; DUARTE, M. F.; FREITAS, V.; PINTADO, M.; SARAIVA, J. A. High-pressure assisted extraction of bioactive compounds from industrial fermented fig by-product. Journal Of Food Science And Technology, [S.L.], v. 54, n. 8, p. 2519-2531, 26 maio 2017b. Disponível em: <http://dx.doi.org/10.1007/s13197-017-2697-2>. DOI: 10.1007/s13197-017-2697-2

ALEXANDRE, E. M.C.; ARAÚJO, P.; DUARTE, M. F.; FREITAS, V.; PINTADO, M.; SARAIVA, J. A.. Experimental Design, Modeling, and Optimization of High-PressureAssisted Extraction of Bioactive Compounds from Pomegranate Peel. Food And Bioprocess Technology, [S.L.], v. 10, n. 5, p. 886-900, 27 jan. 2017a. Springer Science and Business Media LLC. Disponível em: <http://dx.doi.org/10.1007/s11947017-1867-6>. DOI: 10.1007/s11947-017-1867-6

ALVES, J. S. F.; SILVA, A. M. S.; SILVA, R. M.; F.TIAGO, P. R.; CARVALHO, T. G.; et al. In Vivo Antidepressant Effect of Passiflora edulis f. flavicarpa into Cationic Nanoparticles: improving bioactivity and safety. Pharmaceutics, [S.L.], v. 12, n. 4, p. 383, 2020. Disponível em: <http://dx.doi.org/10.3390/pharmaceutics12040383>. DOl: 10.3390/pharmaceutics 12040383 
ANURANJI, C.R.; SHAMINA, S.. Preliminary phytochemical screening and acute \& subacutetoxicity study on different concentrations of unripen fruit peel flour of passiflora edulis in male albino rats. World Journal Of Pharmacy And Pharmaceutical Sciences, [S.I.], v. 7, n. 3, p. 828-834, 2018. Disponível em: <http://dx.doi.org/10.20959/wjpps20183-11113>. DOI: 10.20959/wjpps20183-11113

ANVISA. Agência Nacional de Vigilância Sanitária. Portaria № 27, de 13 de Janeiro de $1998 . \quad$ Disponível em: <https://bvsms.saude.gov.br/bvs/saudelegis/svs1/1998/prt0027_13_01_1998.html> Acessado em: 03 de Setembro 2021.

ANVISA. Agência Nacional de Vigilância Sanitária. Resolução RDC n 54, de 12 de novembro de 2012. Disponível em: <https://bvsms.saude.gov.br/bvs/saudelegis/anvisa/2012/rdc0054_12_11_2012.htm> Acessado em 03 de Setembro 2021

BAZZANO, A.; POTTS, K.; BAZZANO, L.; MASON, J. The Life Course Implications of Ready to Use Therapeutic Food for Children in Low-Income Countries. International Journal Of Environmental Research And Public Health, [S.L.], v. 14, n. 4, p. 403, 11 abr. 2017. Disponível em: <http://doi.org/10.3390/ijerph14040403>. DOI: 10.3390/ijerph14040403

BEZERRA, P. Q. M.; MATOS, M. F. R.; RAMOS, I. G.; MAGALHÃES-GUEDES, K. T.; DRUZIAN, J. I.; et al. Innovative functional nanodispersion: combination of carotenoid from spirulina and yellow passion fruit albedo. Food Chemistry, [S.L.], v. 285, p. 397-405, 2019. Disponível <http://dx.doi.org/10.1016/j.foodchem.2019.01.181>. DOI: 10.1016/j.foodchem.2019.01.181

BISWAS, S.; MISHRA, R.; BIST, A. S.. Passion to Profession: a review of passion fruit processing. Aptisi Transactions On Technopreneurship (Att), [S.L.], v. 3, n. 1, p. 48-56,. 2021. Acesso em: <http://dx.doi.org/10.34306/att.v3i1.143>. DOI: 10.34306/att.v3i1.143

BORDIM, J.; AMORIM, J.; SARI, R.; SILVA, A. C. T.; SOTILES, A. R.; PEREIRA, E. A. Technological Use of Flour Obtained from the Byproducts of Passion Fruit Albedo and the Residue of the Extraction of the Star Fruit Juice in the Formulation of Cereal Bars. Orbital: The Electronic Journal of Chemistry, [S.L.], v.10, n. 3, 2018. Disponível em: <http://dx.doi.org/10.17807/orbital.v10i3.1102>

DOI:10.17807/orbital.v10i3.1102

BOURRÉ, L.; FROHLICH, P.; YOUNG, G.; BORSUK, Y.; SOPIWNYK, E.; et al. Influence of particle size on flour and baking properties of yellow pea, navy bean, and red lentil flours. Cereal Chemistry, [S.L.], v. 96, n. 4, p. 655-667, 2019. Disponível em: <http://dx.doi.org/10.1002/cche.10161>. DOI: 10.1002/cche.10161

CAO, Q.; TENG, J.; WEI, B.; HUANG, L.; XIA, N. Phenolic compounds, bioactivity, and bioaccessibility of ethanol extracts from passion fruit peel based on simulated gastrointestinal digestion. Food Chemistry, [S.L.], v. 356, p. 129682, 2021. 
Disponível em: <http://dx.doi.org/10.1016/j.foodchem.2021.129682>. DOI: 10.1016/j.foodchem.2021.129682

CAZARIN, C. B. B.; SILVA, J. K.; COLOMEU, T. C.; ZOLLNER, R. L.; MARÓSTICA JUNIOR, M. R.. Capacidade antioxidante e composição química da casca de maracujá (Passiflora edulis). Ciência Rural, [S.L.], v. 44, n. 9, p. 1699-1704, 2014. Disponível em: <http://dx.doi.org/10.1590/0103-8478cr20131437>. DOI:10.1590/0103-8478cr20131437

CELUS, M.; KYOMUGASHO, C.; VAN LOEY, A. M.; GRAUWET, T.; HENDRICKX, M.E.. Influence of Pectin Structural Properties on Interactions with Divalent Cations and Its Associated Functionalities. Comprehensive Reviews In Food Science And Food Safety, [S.L.], v. 17, n. 6, p.1576-1594. 2018._Disponível em: <http://dx.doi.org/10.1111/1541-4337.12394.> DOI:10.1111/1541-4337.12394

CHASSAGNE, D.; CROUZET, J. C.; BAYONOVE, C. L.; BAUMES, R. L.. Identification and Quantification of Passion Fruit Cyanogenic Glycosides. Journal Of Agricultural And Food Chemistry, [S.L.], v. 44, n. 12, p. 3817-3820. 1996. Disponível em: <http://dx.doi.org/10.1021/j960381t>. DOI: 10.1021/jf960381t

CHATURVEDI, A. K. . Extraction of Neutraceuticals from Plants by Microwave Assisted Extraction. Systematic Reviews In Pharmacy, [S.L.], v. 9, n. 1, p. 31-35, 2018. Disponível em: <http://dx.doi.org/10.5530/srp.2018.1.6>. DOI: 10.5530/srp.2018.1.6

CHEMAT, F.; ROMBAUT, N.; SICAIRE, A.; MEULlEMIESTRE, A.; FABIANOTIXIER, A.-S.; ABERT-VIAN, M. Ultrasound assisted extraction of food and natural products. Mechanisms, techniques, combinations, protocols and applications. A review. Ultrasonics Sonochemistry, [S.L.], v. 34, p. 540-560, 2017._Disponível em: <http://dx.doi.org/10.1016/j.ultsonch.2016.06.035>.

10.1016/j.ultsonch.2016.06.035

COELHO, E. M; AZEVÊDO, L. C; VIANA, A. C; RAMOS, I. G; GOMES, R. G; et al. Physico-chemical properties, rheology and degree of esterification of passion fruit (Passiflora edulis f.flavicarpa) peel flour. Journal Of The Science Of Food And Agriculture, [S.L.], v. 98, n. 1, p. 166-173, 2017a._Disponível em: <http://dx.doi.org/10.1002/jsfa.8451>. DOI: 10.1002/jsfa.8451

COELHO, E. M; GOMES, R. G. ; MACHADO, B. A. S.; OLIVEIRA, R. S.; LIMA, M. S.; et al. Passion fruit peel flour - Technological properties and application in food products. Food Hydrocolloids, [S.L.], v. 62, p. 158-164, 2017b._Disponível em: <http://dx.doi.org/10.1016/j.foodhyd.2016.07.027>. DOI: 10.1016/j.foodhyd.2016.07.027

CONSTANTINO, J. S. F.; VIEIRA, A. F.; SOUSA, L. M.; ALMEIDA, R. D.; LOPES, J. D. Aproveitamento da casca de jabuticaba e maracujá para elaboração de pão de forma funcional. Gestão Integrada de Resíduos: Universidade \& Comunidade, S.I., v. $3, \quad$ n. $1, \quad$ p. 40-43, 2018. Disponível em: $<$ https://www.researchgate.net/profile/Paulo-Roberto-

Francisco/publication/322901570_Gestao_integrada_de_residuos_universidade_co 
munidade_v3/links/5a74f704a6fdccbb3c058f2e/Gestao-integrada-de-residuosuniversidade-comunidade-v3.pdf>.

CONTI-SILVA, A. C.; RONCARI, R. F. Sensory features and physical-chemical characterization of Brazilian honey bread with passion fruit peel flour. Nutrition \& Food Science, [S.L.], v. 45, n. 4, p. 595-605, 2015._Disponível em: <http://dx.doi.org/10.1108/nfs-03-2015-0023>. DOI: 10.1108/nfs-03-2015-0023

CORRÊA, E.M. MEDINA, L.; BARROS-MONTEIRO, J.; VALLE, N.O.; SALES, R. et al. The intake of fiber mesocarp passionfruit (passiflora edulis) lowers levels of triglyceride and cholesterol decreasing principally insulin and leptin. The journal of aging research \& clinical practice., [S.L.], n. 4, p. 31-35, dez. 2014. Disponível em: <https://www.ncbi.nlm.nih.gov/pmc/articles/PMC4205930/>.

COSTA, R. C. N.; FERREIRA, N. L. B.; ANDRADE, R. O. Physicochemical and Microbiological Analysis of Passion Fruit and Cachaça Jelly Added from Albedo as a Source of Pectin, and Molasses as a Source of Sugar. Journal Of Culinary Science \& Technology, [S.L.], p. 1-17. 2021. Disponível em: <http://dx.doi.org/10.1080/15428052.2021.1914262>. DOI: $10.1080 / 15428052.2021 .1914262$

CRESSEY, P.; SAUNDERS, D.; GOODMAN, J.. Cyanogenic glycosides in plantbased foods available in New Zealand. Food Additives \& Contaminants: Part A, [S.L.], v. $30, \quad$ n. $11, \quad$ p. 1946-1953. 2013. Disponível em: <http://dx.doi.org/10.1080/19440049.2013.825819>. DOI: 10.1080/19440049.2013.825819

DAO, T. A. T.; WEBB, H. K.; MALHERBE, F. Optimization of pectin extraction from fruit peels by response surface method: conventional versus microwave-assisted heating. Food Hydrocolloids, [S.L.], v. 113, p. 106475, 2021. Disponível em: $<$ http://dx.doi.org/10.1016/j.foodhyd.2020.106475>.

10.1016/j.foodhyd.2020.106475

DIAS, M. V.; FIGUEIREDO, L. P.; VALENTE, W. A.; FERRUA, F. Q.; PEREIRA, P. A. P.; et al. Estudo de variáveis de processamento para produção de doce em massa da casca do maracujá (Passiflora edulis f. flavicarpa). Ciência e Tecnologia de Alimentos, [S.L.], v. 31, n. 1, p. 65-71. 2011. Disponível em: <https://doi.org/10.1590/S0101-20612011000100008>. DOI:10.1590/S010120612011000100008

DONAGHY, J.A.; MCKAY, A.M.. Pectin extraction from citrus peel by polygalacturonase produced on whey. Bioresource Technology, [S.L.], v. 47, n. 1, p. 25-28. 1994. Disponível em: <http://dx.doi.org/10.1016/0960-8524(94)90024-8>. DOI: 10.1016/0960-8524(94)90024-8.

DRANCA, F.; VARGAS, M.; OROIAN, M.. Physicochemical properties of pectin from Malus domestica 'Fălticeni' apple pomace as affected by non-conventional extraction techniques. Food Hydrocolloids, [S.L.], v. 100, p. 105383, 2020. Disponível em: <http://dx.doi.org/10.1016/j.foodhyd.2019.105383>.

DOI: 10.1016/j.foodhyd.2019.105383 
FERRARI, R. A.; COLUSSI, F.; AYUB, R. A.. Caracterização de subprodutos da industrialização do maracujá-aproveitamento das sementes. Revista Brasileira de Fruticultura, [S.L.], v. 26, n. 1, p. 101-102, 2004. Disponível em: <https://doi.org/10.1590/S0100-29452004000100027>. DOI: 10.1590/S010029452004000100027

FERREIRA, M. P.; TARLEY, C. R. T.. Bioaccessibility estimation of metallic macro and micronutrients $\mathrm{Ca}, \mathrm{Mg}, \mathrm{Zn}, \mathrm{Fe}, \mathrm{Cu}$ and $\mathrm{Mn}$ in flours of oat and passion fruit peel. LWT: Food sciency and technology, [S.L.], v. 150, p.111880, out. 2021. Disponível em: <https://doi.org/10.1016/j.Iwt.2021.111880> DOI: 10.1016/j.Iwt.2021.111880

FOGAGNOLI, G.; SERAVALLI, E. A. G.. Aplicação de farinha de casca de maracujá em massa alimentícia fresca. Brazilian Journal Of Food Technology, [S.L.], v. 17, n. 3, p. 204-212. 2014. Disponível em: <http://dx.doi.org/10.1590/1981-6723.0614>. DOI: $10.1590 / 1981-6723.0614$

FREITAS, C. M. P.; SOUSA, R. C. S.; DIAS, M. M. S.; COIMBRA, J. S. R.. Extraction of Pectin from Passion Fruit Peel. Food Engineering Reviews, [S.L.], v. 12, n. 4, p. 460-472. 2020. Disponível em: <http://dx.doi.org/10.1007/s12393-020-09254-9>. DOI: $10.1007 / \mathrm{s} 12393-020-09254-9$

GALISTEO, M; DUARTE, J; ZARZUELO, A. Effects of dietary fibers on disturbances clustered in the metabolic syndrome. The Journal Of Nutritional Biochemistry, [S.L.], v. 19, n. 2, p. 71-84. 2008. Disponível em: <http://dx.doi.org/10.1016/j.jnutbio.2007.02.009>. DOI: 10.1016/j.jnutbio.2007.02.009

GARCIA, M. V; MILANI, M.; RIES, E. F. Production optimization of passion fruit peel flour and its incorporation into dietary food. Food Science And Technology International, [S.L.], v. 26, n. 2, p. 132-139. 2019. Disponível em: <http://dx.doi.org/10.1177/1082013219870011>. DOI: 10.1177/1082013219870011

GARCIA-GARCIA, G.; RAHIMIFARD, S.; MATHARU, A. S.; DUGMORE, T. I. J.. LifeCycle Assessment of Microwave-Assisted Pectin Extraction at Pilot Scale. ACS Sustainable Chemistry \& Engineering, [S.L.], v. 7, n. 5, p. 5167-5175, 4 fev. 2019. Disponível em: <http://dx.doi.org/10.1021/acssuschemeng.8b06052>. DOI: 10.1021 /acssuschemeng.8b06052

GOMES, T. R.; FREITAS, E. R.; WATANABE, P. H.; FERREIRA, A. C. S.; TAVARES, L. M. S.. Passion Fruit Peel in Growing Rabbits Feed. Revista Ciência Agronômica, [S.L.], v. 52, n. 4, p. 1-11, 2021. Disponível em: <http://dx.doi.org/10.5935/1806-6690.20210051>. DOI: 10.5935/18066690.20210051

GRISI, M. C. M.; FALEIRO, F. G.; JUNQUEIRA, N. T. V.; OLIVEIRA, J. S.. Genetic Variability of Passion Fruit Multispecific Hybrids and Their Respective Wild Parents Determined by Microsatellite Markers. Journal Of Agricultural Science, [S.L.], v. 11, n. 10, p. 302, 2019. Disponível em: <https://doi.org/10.5539/jas.v11n10p302>. DOI: 10.5539/jas.v11n10p302 
HAN, W.; MENG, Y.; HU, C.; DONG, G.; QU, Y.; DENG, H.; GUO, Y.. Mathematical model of $\mathrm{Ca} 2+$ concentration, $\mathrm{pH}$, pectin concentration and soluble solids (sucrose) on the gelation of low methoxyl pectin. Food Hydrocolloids, [S.L.], v. 66, p. 37-48, 2017. Disponível em: <http://dx.doi.org/10.1016/j.foodhyd.2016.12.011>. DOI: 10.1016/j.foodhyd.2016.12.011

HE, X.; LUAN, F.; YANG, Y.; WANG, Z.; ZHAO, Z.; et al. Passiflora edulis: an insight into current researches on phytochemistry and pharmacology. Frontiers In Pharmacology, [S.L.], v. 11, p. 1-16, 2020. Disponível em: <http://dx.doi.org/10.3389/fphar.2020.00617>. DOI: 10.3389/fphar.2020.00617

HOSSEINI, S. S.; KHODAIYAN, F.; YARMAND, M. S.. Optimization of microwave assisted extraction of pectin from sour orange peel and its physicochemical properties. Carbohydrate Polymers, [S.L.], v. 140, p. 59-65, 2016._Disponível em: $\leq$ http://dx.doi.org/10.1016/j.carbpol.2015.12.051>.

10.1016/j.carbpol.2015.12.051

ICHIMURA, T.; YAMANAKA, A.; ICHIBA, T.; TOYOKAWA, T.; KAMADA, Y.; et al. Antihypertensive Effect of an Extract of Passiflora edulis Rind in Spontaneously Hypertensive Rats. Bioscience, Biotechnology, And Biochemistry, [S.L.], v. 70, n. 3, p. 718-721. 2006. Disponível em: <http://dx.doi.org/10.1271/bbb.70.718>. DOI: $10.1271 /$ bbb.70.718

IMIG, D. C.; MILWARD-DE-AZEVEDO, M. A.; CERVI, A. C. Passifloraceae sensu stricto de Minas Gerais, Brasil. Rodriguésia, [S.L.], v. 69, n. 4, p. 1701-1735, 2018. Disponível em: <https://doi.org/10.1590/2175-7860201869415>. DOI: 10.1590/21757860201869415

IBGE - Instituto Brasileiro de Geografia e Estatística. Produção Agropecuária 2020. Rio de Janeiro, $2019 . \quad$ Disponível em:< https://www.ibge.gov.br/explica/producao-agropecuaria/maracuja/mg>. Acesso em: 25 de Novembro de 2021.

JEONG, H.; KIM, H; AHN, S. H.; OH, S. C.; YANG, I.; et al. Optimization of enzymatic hydrolysis conditions for extraction of pectin from rapeseed cake (Brassica napus L.) using commercial enzymes. Food Chemistry, [S.L.], v. 157, p. 332-338 2014. Disponível em: <http://dx.doi.org/10.1016/j.foodchem.2014.02.040>; DOI: 10.1016/j.foodchem.2014.02.040

KANDANDAPANI, S.; BALARAMAN, A. K.; AHAMED, H. N.. Extracts of passion fruit peel and seed of Passiflora edulis (Passifloraceae) attenuate oxidative stress in diabetic rats. Chinese Journal Of Natural Medicines, [S.L.], v. 13, n. 9, p. 680-686, 2015. Disponível em: http://dx.doi.org/10.1016/s1875-5364(15)30066-2. DOI: 10.1016/s1875-5364(15)30066-2.

KARACA, O. B.; SAYDAM, I. B.; GÜVEN, M.. Physical, chemical, and sensory attributes of lowfat, fullat, and fatfree probiotic set yogurts fortified with fiberrich persimmon and apple powders. Journal Of Food Processing And Preservation, [S.L.], v. 43, n. 6, p. 1-13,. 2019. Disponível em: <http://dx.doi.org/10.1111/jfpp.13926>. DOI: 10.1111/jfpp.13926 
KRÓL, E.; BOGDANSKI, P.; SULIBURSKA, J.; KREJPCIO, Z.. The Relationship between Dietary, Serum and Hair Levels of Minerals ( $\mathrm{Fe}, \mathrm{Zn}, \mathrm{Cu}$ ) and Glucose Metabolism Indices in Obese Type 2 Diabetic Patients. Biological Trace Element Research, [S.L.], v. 189, n. 1, p. 34-44, 2018. Disponível em: <http://dx.doi.org/10.1007/s12011-018-1470-3>. DOI: 10.1007/s12011-018-1470-3

LAZZARI, A.; BARBOSA, H. D.; SILVA, I. C.; SILVA, L. H. M.; DADA, A. P. et al. Potencial antioxidante de resíduos agroindustriais de frutas tropicais: revisão. Research, Society And Development, [S.L.], v. 10, n. 3, p. 1-7, 16 mar. 2021. Disponível em: <http://dx.doi.org/10.33448/rsd-v10i3.13357>. DOI: 10.33448/rsdv10i3.13357

LEWIS, B. J.; HERRLINGER, K. A.; CRAIG, T. A.; MEHRING-FRANKLIN, C. E.; DEFREITAS, Z.; et al. Antihypertensive effect of passion fruit peel extract and its major bioactive components following acute supplementation in spontaneously hypertensive rats. The Journal Of Nutritional Biochemistry, [S.L.], v. 24, n. 7, p. 1359-1366, 2013._Disponível em: <http://dx.doi.org/10.1016/j.jnutbio.2012.11.003>. DOI: 10.1016/j.jnutbio.2012.11.003

LIEW, S. Q.; CHIN, N. L.; YUSOF, Y. A. Extraction and Characterization of Pectin from Passion Fruit Peels. Agriculture And Agricultural Science Procedia, [S.L.], v. 2, p. 231-236, 2014. Disponível em: <https://doi.org/10.1016/j.aaspro.2014.11.033>. DOI: 10.1016/j.aaspro.2014.11.033

LIMA, G. C.; VUOLO, M. M.; BATISTA, A. G.; DRAGANO, N. R. V.; SOLON, C.; et al. Passiflora edulis peel intake improves insulin sensitivity, increasing incretins and hypothalamic satietogenic neuropeptide in rats on a high-fat diet. Nutrition, [S.L.], v. 32, n. 7-8, p. 863-870, 2016. Disponível em: <http://doi.org/10.1016/j.nut.2016.01.014>. DOI: 10.1016/j.nut.2016.01.014

LIU, A; HUANG, B.; LEI, L.; LU, Y.; ZHOU, J.; et al. Production of high antioxidant activity flavonoid monoglucosides from citrus flavanone with immobilised $\alpha \cdot L$ ' rhamnosidase in one step. International Journal Of Food Science \& Technology, [S.L.], v. 54, n. 10, p. 2854-2862, 2019._Disponível em: <http://dx.doi.org/10.1111/ijfs.14202>. DOI: 10.1111/ijfs.14202

LÓPEZ-VARGAS, J. H.; FERNÁNDEZ-LÓPEZ, J.; PÉREZ-ÁLVAREZ, J. A.; VIUDAMARTOS, M. Chemical, physico-chemical, technological, antibacterial and antioxidant properties of dietary fiber powder obtained from yellow passion fruit (Passiflora edulis var. flavicarpa) co-products. Food Research International, [S.L.], v. 51, n. 2, p. 756-763, 2013. Disponível em: <https://doi.org/10.1016/j.foodres.2013.01.055>. DOI: 10.1016/j.foodres.2013.01.055

MARCHINI, M.; CARINI, E.; CATALDI, N.; BOUKID, F.; BLANDINO, M; et al. The use of red lentil flour in bakery products: how do particle size and substitution level affect rheological properties of wheat bread dough?. LWT, [S.L.], v. 136, p. 110299, 2021. Disponível em: <http://dx.doi.org/10.1016/j.lwt.2020.110299>. DOI: 10.1016/j.Iwt.2020.110299 
MARQUES, F. Z.; NELSON, E.; CHU, P; HORLOCK, D.; FIEDLER, A.; et al. HighFiber Diet and Acetate Supplementation Change the Gut Microbiota and Prevent the Development of Hypertension and Heart Failure in Hypertensive Mice. Circulation, [S.L.], v. 135, n. 10, p. 964-977, 2017. Disponível em: <http://dx.doi.org/10.1161/circulationaha.116.024545>.

10.1161/circulationaha.116.024545

MARREIRO, D.; CRUZ, K.; MORAIS, J.; BESERRA, J.; SEVERO, J.; et al. Zinc and Oxidative Stress: current mechanisms. Antioxidants, [S.L.], v. 6, n. 2, p. 24, 2017. Disponível em: <http://dx.doi.org/10.3390/antiox6020024>. DOI: 10.3390/antiox6020024

MARTíNeZ, R.; TORRES, P.; MENESES, M.A.; FIGUEROA, J.G.; PÉREZÁLVAREZ, J.A.; et al. Chemical, technological and in vitro antioxidant properties of cocoa (Theobroma cacao L.) co-products. Food Research International, [S.L.], v. 49, n. 1, p. 39-45, 2012. Disponível em: <http://dx.doi.org/10.1016/j.foodres.2012.08.005>. DOI: 10.1016/j.foodres.2012.08.005

MARTINS, H. F.; CARVALHO, S. S. R. A.; BISPO, J. A. C.; SOUZA, S. M. A.; MARTINEZ, E. A. Maracujá-amarelo (Passiflora edulis f. Flavicarpa): cinética da secagem artificial e natural da casca. Brazilian Journal Of Development, [S.L.], v. 5, n. 11, p. 23234-23245, 2019. Disponível em: <http://dx.doi.org/10.34117/bjdv5n11044>. DOI: $10.34117 /$ bjdv5n11-044

MAZZA, K. E. L.; SANTIAGO, M. C. P. A.; NASCIMENTO, L. S. M.; GODOY, R. L. O.; SOUZA, Erika F.; Syrah grape skin valorization using ultrasound - assisted extraction: phenolic compounds recovery, antioxidant capacity and phenolic profile. International Journal Of Food Science \& Technology, [S.L.], v. 54, n. 3, p. 641650. 2018. Disponível em: <http://dx.doi.org/10.1111/ijfs.13883>. DOI: $10.1111 /$ ijfs. 13883

MEDEIROS, J. S.; DINIZ, M. F. F. M.; SRUR, A. U. O. S. ; PESSOA, M. B.; CARDOSO, M. A. A.; et al. Ensaios toxicológicos clínicos da casca do maracujáamarelo (Passiflora edulis, f. flavicarpa), como alimento com propriedade de saúde. Revista Brasileira de Farmacognosia, [S.L.], v. 19, n. 2, p. 394-399, 2009. Disponível em: <http://dx.doi.org/10.1590/s0102-695x2009000300010>. DOI: $10.1590 / \mathrm{s} 0102-695 \times 2009000300010$

MELETTI, L. M. M. Avanços na cultura do maracujá no Brasil. Revista Brasileira de Fruticultura, [S.L.], v. 33, n. 1, p. 83-91, 2011 Disponível em: <https://doi.org/10.1590/S0100-29452011000500012>. DOI: 10.1590/S010029452011000500012

MENDES, R. M. L.; ANDRADE, R. H. C.; MARQUES, M. F. F.; ANDRADE, E. R. Potential use of the passion fruit from caatinga in kefir. Food Bioscience, [S.L.], v. 39, p. 100809, 2021._Disponível em: <http://dx.doi.org/10.1016/j.fbio.2020.100809>. DOI: $10.1016 /$ j.fbio.2020.100809 
MIAO, X.; SUN, W.; MIAO, L.; FU, Y.; WANG, Y.; et al. Zinc and Diabetic Retinopathy. Journal Of Diabetes Research, [S.L.], v. 2013, p. 1-8, 2013. Disponível em: <http://dx.doi.org/10.1155/2013/425854>. DOI: 10.1155/2013/425854

MONTEIRO, S. A.; BESERRA, Y. A. S.; OLIVEIRA, H. M. L.; PASQUALI, M. Production of Probiotic Passion Fruit (Passiflora edulis Sims f. flavicarpa Deg.) Drink Using Lactobacillus reuteri and Microencapsulation via Spray Drying. Foods, [S.L.], v. 9 , n. 3, p. 335, 2020._Disponível em: <http://dx.doi.org/10.3390/foods9030335>. DOI: $10.3390 /$ foods 9030335

NADAR, S. S.; RAO, P.; RATHOD, V.K. Enzyme assisted extraction of biomolecules as an approach to novel extraction technology: a review. Food Research International, [S.L.], v. 108, p. 309-330, 2018. Disponível em: $<$ http://dx.doi.org/10.1016/j.foodres.2018.03.006>.

10.1016/j.foodres.2018.03.006

NASCIMENTO, E. M. G. C.; ASCHERI, J. L. R.; CARVALHO, C. W. P; GALDEANO, M. C.. Benefícios e perigos do aproveitamento da casca de maracujá (Passiflora edulis) como ingrediente na produção de alimentos. Instituto Adolfo Lutz, São Paulo, v. 72, p. 1-11, 2013. Disponível em: <https://ainfo.cnptia.embrapa.br/digital/bitstream/item/92439/1/2013-147.pdf>.

NASCIMENTO, E. M.G.C.; MULET, A.; ASCHERI, J. L. R.; CARVALHO, C. W. P.; CÁRCEL, J. A.. Effects of high-intensity ultrasound on drying kinetics and antioxidant properties of passion fruit peel. Journal Of Food Engineering, [S.L.], v. 170, p. 108118, 2016. Disponível em: <http://dx.doi.org/10.1016/j.jfoodeng.2015.09.015>. DOI: 10.1016/j.jfoodeng.2015.09.015

NASCIMENTO, T.A.; CALADO, V.; CARVALHO, C.W.P.. Development and characterization of flexible film based on starch and passion fruit mesocarp flour with nanoparticles. Food Research International, [S.L.], v. 49, n. 1, p. 588-595, 2012. Disponível em: $\quad<$ http://dx.doi.org/10.1016/j.foodres.2012.07.051>. DOI: 10.1016/j.foodres.2012.07.051

NING, X.; WU, J.; LUO, Z.; CHEN, Y.; MO, Z. et al. Cookies fortified with purple passion fruit epicarp flour: impact on physical properties, nutrition, in vitro starch digestibility, and antioxidant activity. Cereal Chemistry, [S.L.], v. 98, n. 2, p. 328336, 2020._Disponível em: <http://dx.doi.org/10.1002/cche.10367>. DOI: $10.1002 /$ cche.10367

NOVAES, C. G.; ROMÃO, I. L. S.; SANTOS, B. G.; RIBEIRO, J. P.; BEZERRA, M. A.; et al. Screening of Passiflora L. mineral content using principal component analysis and Kohonen self-organizing maps. Food Chemistry, [S.L.], v. 233, p. 507513. 2017. Disponível em: <https://doi.org/10.1016/j.foodchem.2017.04.111>. DOI: 10.1016/j.foodchem.2017.04.111

NUGRAHA, S. E.; ACHMAD, S.; SITOMPUL, E. Antibacterial Activity of Ethyl Acetate Fraction of Passion Fruit Peel (Passiflora Edulis Sims) on Staphylococcus Aureus and Escherichia Coli. IndonesianJournal Of Pharmaceutical And Clinical 
Research, [S.L.], v. 2, n. 1, p. 07-12, 2019. Disponível em: <http://dx.doi.org/10.32734/idjpcr.v2i1.972>. DOI: 10.32734/idjpcr.v2i1.972

NUGRAHA, S. E.; ACHMAD, S.; SITOMPUL, E.. Antibacterial activity of Ethanol Extract of Purple Passion Fruit Peel (Passiflora edulis Sims) on Staphylococcus aureus and Escherichia coli. Indonesian Journal Of Pharmaceutical And Clinical Research, [S.L.], v. 1, n. 2, p. 29-34, 31 dez. 2018. Disponível em: <http://dx.doi.org/10.32734/idjpcr.v1i2.606>. DOI: 10.32734/idjpcr.v1i2.606

OLIVEIRA, A. C.; VALENTIM, I. B.; SILVA, C. A.; BECHARA, E. J. H.; BARROS, M. $P$. et al. Total phenolic content and free radical scavenging activities of methanolic extract powders of tropical fruit residues. Food Chemistry, [S.L.] v. 115, n. 2, p. 469475, 2009. Disponível em: <http://dx.doi.org/10.1016/j.foodchem.2008.12.045>. DOI: 10.1016/j.foodchem.2008.12.045

OLIVEIRA, C. F; GURAK, P. D.; CLADERA-OLIVERA, F.; MARCZAK, L. D. F.; KARWE, M. Combined Effect of High-Pressure and Conventional Heating on Pectin Extraction from Passion Fruit Peel. Food And Bioprocess Technology, [S.L.], v. 9, n. 6, p. 1021-1030, 2016a. Disponível em: <http://doi.org/10.1007/s11947-016-16914>. DOI: $10.1007 / \mathrm{s} 11947-016-1691-4$

OLIVEIRA, L. C.; SANTOS, J. A. B.; NARAIN, N.; FONTES, A. S.; CAMPOS, R. S. S.; et al. Caracterização e extração de compostos voláteis de resíduos do processamento de maracujá (Passiflora edulis Sims f. flavicarpa degener). Ciência Rural, [S.L.], v. 42, n. 12, p. 2280-2287,. 2012. Disponível em: <http://doi.org/10.1590/S0103-84782012005000103>. DOI: 10.1590/S010384782012005000103

OLIVEIRA, P. T. F.; SANTOS, E. L.; SILVA, W. A. V.; FERREIRA, M. R. A.; SOARES, L. A. Production of biomolecules of interest to the anxiolytic herbal medicine industry in yellow passionfruit leaves ( Passiflora edulis f. flavicarpa ) promoted by mycorrhizal inoculation. Journal Of The Science Of Food And Agriculture, [S.L.], v. 99, n. 7, p. 3716-3720, 2019. Disponível em: <http://dx.doi.org/10.1002/jsfa.9598>. DOI: 10.1002/jsfa.9598

OLIVEIRA, V. R.; PRETO, L. T.; SCHMIDT, H. O.; KOMEROSKI, M.; SILVA, V. L.; et al. Physicochemical and sensory evaluation of cakes made with passion fruit and orange residues. Journal Of Culinary Science \& Technology, [S.L.], v. 14, n. 2, p. 166-175, 2016b. Disponível em: $<$ https://www.tandfonline.com/doi/abs/10.1080/15428052.2015.1102787?tab=permis sions\&scroll=top $>$.

PERINA, N.P.; GRANATO, D.; HIROTA, C.; CRUZ, A.G.; BOGSAN, C.s.B.; OLIVEIRA, M.N.. Effect of vegetal-oil emulsion and passion fruit peel-powder on sensory acceptance of functional yogurt. Food Research International, [S.L.], v. 70, p. 134-141, 2015._Disponível em: <http://dx.doi.org/10.1016/j.foodres.2015.01.014>. DOI: 10.1016/j.foodres.2015.01.014

QUEIROZ, M. S. R.; JANEBRO, D. I.; CUNHA, M. A. L.; MEDEIROS, J. S. ; SABAASRUR, A. U. O; et al. Effect of the yellow passion fruit peel flour (Passiflora edulis $\mathrm{f}$. 
flavicarpa deg.) in insulin sensitivity in type 2 diabetes mellitus patients. Nutrition Journal, [S.L.], v. 11, n. 1, p. 1-7, 2012. Disponível em: <http://dx.doi.org/10.1186/1475-2891-11-89>. DOI: 10.1186/1475-2891-11-8

RAMLI, A. N. M.; MANAP, N. W. A.; BHUYAR, P.; AZELEE, N. I. W.. Passion fruit (Passiflora edulis) peel powder extract and its application towards antibacterial and antioxidant activity on the preserved meat products. Sn Applied Sciences, [S.L.], v. 2, n. 10, p. 1-11, 2020. Disponível em: <http://dx.doi.org/10.1007/s42452-020-03550z>. DOI: $10.1007 / s 42452-020-03550-z$

REIS, L. C. R.; FACCO, E. M. P.; SALVADOR, M.; FLÔRES, S. H.; RIOS, A. O.. Characterization of Orange Passion Fruit Peel Flour and Its Use as an Ingredient in Bakery Products. Journal Of Culinary Science \& Technology, [S.L.], v. 18, n. 3, p. 214-230,. 2018.2 Disponível em: <http://dx.doi.org/10.1080/15428052.2018.1564103>. DOI: 10.1080/15428052.2018.1564103

RIBEIRO, T. H. S.; BOLANHO, B. C.; MONTANUCI, F. D.; RUIZ, S. P.. Physicochemical and sensory characterization of gluten-free fresh pasta with addition of passion fruit peel flour. Ciência Rural, [S.L.], v. 48, n. 12, p. 1-9, 2018._Disponível em: <http://dx.doi.org/10.1590/0103-8478cr20180508>. DOI: 10.1590/01038478 cr20180508

ROUT, J. R.; SAHOO, S. L.; DAS, R.; RAM, S. S.; CHAKRABORTY, A.; SUDARSHAN, M. Changes in Antioxidant Enzyme Activities and Elemental Profiling of Abutilon indicum L. Subjected to Copper Stress. Proceedings Of The National Academy Of Sciences, India Section B: Biological Sciences, [S.L.], v. 87, n. 4, p. 1469-1478, 2016. Disponível em: <http://dx.doi.org/10.1007/s40011-016-0725-z>. DOI: $10.1007 / s 40011-016-0725-z$

SANTOS, K. L.; ALVES, C. A. N.; SOUSA, F. M. ; GUSMÃO, T. A. S.; ALVES FILHO, E. G.; et al. Chemometrics applied to physical, physicochemical and sensorial attributes of chicken hamburgers blended with green banana and passion fruit epicarp biomasses. International Journal Of Gastronomy And Food Science, [S.L.], v. 24, p. 100337. 2021._Disponível em: shttp://dx.doi.org/10.1016/j.ijgfs.2021.100337>. DOI: 10.1016/j.ijgfs.2021.100337

SEIXAS, F. L.; FUKUDA, D. L.; TURBIANI, F. R. B.; GARCIA, P. S.; PETKOWICZ, C. L. O. et al. Extraction of pectin from passion fruit peel (Passiflora edulis f. flavicarpa) by microwave-induced heating. Food Hydrocolloids, [S.L.], v. 38, p. 186-192, 2014. Disponível em: <http://dx.doi.org/10.1016/j.foodhyd.2013.12.001>. DOI: 10.1016/j.foodhyd.2013.12.001

SILLERO, L.; PRADO, R.; LABIDI, J. Simultaneous microwave-ultrasound assisted extraction of bioactive compounds from bark. Chemical Engineering And Processing - Process Intensification, [S.L.], v. 156, p. 108100, 2020. Disponível em: <http://dx.doi.org/10.1016/j.cep.2020.108100>. DOI: 10.1016/j.cep.2020.108100

SILVA, D. C.; FREITAS, A. L. P.; BARROS, F. C. N.; LINS, K. O. A. L.; ALVES, A. P. N. N.; et al.. Polysaccharide isolated from Passiflora edulis: characterization and 
antitumor properties. Carbohydrate Polymers, [S.L.], v. 87, n. 1, p. 139-145, 2011. Disponível em: <http://dx.doi.org/10.1016/j.carbpol.2011.07.029>. DOI: 10.1016/j.carbpol.2011.07.029

SILVA, E. C. O.; SILVA, W. P.; SILVA, E. T.; LOPES, J. D.; GUSMÃO, R. P.. Obtenção e caracterização da farinha do albedo de maracujá (Passiflora edulis f. Flavicarpa) para uso alimentício. Revista Verde de Agroecologia e Desenvolvimento Sustentável, [S.L.], v. 11, n. 3, p. 69, 2016. Disponível em: <http://dx.doi.org/10.18378/rvads.v11i3.4062>. DOI: 10.18378/rvads.v11i3.4062

SILVA, J. K.; CAZARIN, C. B. B; BATISTA, A. G.; MARÓSTICA, M. Effects of passion fruit (Passiflora edulis) byproduct intake in antioxidant status of Wistar rats tissues. LWT - Food Science And Technology, [S.L.], v. 59, n. 2, p. 1213-1219, 2014. Disponível em: <http://dx.doi.org/10.1016/j.lwt.2014.06.060>. DOI: 10.1016/j.Iwt.2014.06.060

SOUSA, D. F.; VERAS, V. S.; FREIRE, V. E.C.; PAULA, M. L.; SERRA, M. A. A.O. et al. Effectiveness of Passion Fruit Peel Flour (Passiflora edulis L.) versus Turmeric Flour (Curcuma longa L.) on Glycemic Control: systematic review and metaanalysis. Current Diabetes Reviews, [S.L.], v. 16, n. 5, p. 450-456, 2020. Disponível em: $\quad<h t t p: / / d x . d o i . o r g / 10.2174 / 1573399815666191026125941>$. DOl: $10.2174 / 1573399815666191026125941$

SOUZA, C. B.; JONATHAN, M.; SAAD, S. M. I.; SCHOLS, H. A.; VENEMA, K. Characterization and in vitro digestibility of by-products from Brazilian food industry: cassava bagasse, orange bagasse and passion fruit peel. Bioactive Carbohydrates And Dietary Fibre, [S.L.], v. 16, p. 90-99, 2018. Disponível em: <http://dx.doi.org/10.1016/j.bcdf.2018.08.001>. DOI: 10.1016/j.bcdf.2018.08.001

SOUZA, C. G; RODRIGUES, T. H.; SILVA, L. M.; RIBEIRO, P. R.; BRITO, E. S. Sequential extraction of flavonoids and pectin from yellow passion fruit rind using pressurized solvent or ultrasound. Journal of The Science Of Food And Agriculture, [S.L.], v. 98, n. 4, p. 1362-1368, 2017. Disponível em: <http://dx.doi.org/10.1002/jsfa.8601 >. DOI: 10.1002/jsfa.8601

SOUZA, C. V. B.; BELLUCCI, E. R. B.; LORENZO, J. M.; BARRETTO, A. C. S. Lowfat Brazilian cooked sausage-Paio - with added oat fiber and inulin as a fat substitute: effect on the technological properties and sensory acceptance. Food Science And Technology, [S.L.], v. 39, n. 1, p. 295-303, 2019a. Disponível em: <http://dx.doi.org/10.1590/fst.03618>. DOI: 10.1590/fst.03618

SOUZA, F. G.; BARBOSA, F. F.; RODRIGUES, F. M. Avaliação da geleia de tamarindo sem pectina e com pectina proveniente do albedo do maracujá amarelo. Journal Of Bioenergy And Food Science, [S.L.], p. 78-88, 2016. Disponível em: <http://dx.doi.org/10.18067/jbfs.v3i2.52>. DOI: 10.18067/jbfs.v3i2.52

SOUZA, V. F.; ASCHERI, J. L. R.; ASCHERI, D. P. R. Characterization and Potential Application of Blend of Passion Fruit Peel with Rice Flour in an Extruded Product for Fiber Enhancement. Journal Of Food And Nutrition Research, [S.L.], v. 7, n. 7, p. 
522-529, 2019b. Disponível em: <http://dx.doi.org/10.12691/jfnr-7-7-6>. DOI: 10.12691/jfnr-7-7-6

SPENCER, K. C.; SEIGLER, D.S.. Cyanogenesis of Passiflora edulis. Journal of Agricultural And Food Chemistry, [S.L.], v. 31, n. 4, p. 794-796, 1983._Disponível em: <http://dx.doi.org/10.1021/jf00118a028>. DOI: 10.1021/jf00118a028

SULERIA, H. A. R.; BARROW, C. J.; DUNSHEA, F. R. Screening and Characterization of Phenolic Compounds and Their Antioxidant Capacity in Different Fruit Peels. Foods, [S.L.], v. 9, n. 9, p. 1206, 2020. Disponível em: <http://dx.doi.org/10.3390/foods9091206>. DOI: 10.3390/foods9091206

SUN, L.; WU, D.; NING, X.; YANG, G.; LIN, Z.; et al. $\alpha$-Amylase-assisted extraction of polysaccharides from Panax ginseng. International Journal Of Biological Macromolecules, [S.L.], v. 75, p. 152-157, 2015._Disponível em: <http://dx.doi.org/10.1016/j.jibiomac.2015.01.025>. 10.1016/j.ijbiomac.2015.01.025.

TOHIDI, B.; RAHIMMALEK, M.; ARZANI, A. Essential oil composition, total phenolic, flavonoid contents, and antioxidant activity of Thymus species collected from different regions of Iran. Food Chemistry, [S.L.], v. 220, p. 153-161, 2017._Disponível em: $<$ http://dx.doi.org/10.1016/j.foodchem.2016.09.203>. 10.1016/j.foodchem.2016.09.203

VASCO-CORREA, J.; ZAPATA, A. D. Enzymatic extraction of pectin from passion fruit peel (Passiflora edulis f. flavicarpa) at laboratory and bench scale. LWT, [S.L.], v. 80, p. 280-285, 2017._Disponível em: <http://dx.doi.org/10.1016/j.lwt.2017.02.024>. DOI: $10.1016 /$ J.Iwt.2017.02.024

VERNAZA, G.; MATSUURA, F. C. A. U.; CHANG, Y. K.; STEEL, C.J. Effect of Some Extrusion Variables on Residual Quantity of Cyanogenic Compounds in an Organic Breakfast Cereal Containing Passion Fruit Fiber. Cereal Chemistry Journal, [S.L.], v. 86, n. 3, p. 302-306, 2009. Disponível em: <http://dx.doi.org/10.1094/cchem-86-30302>. DOI: $10.1094 /$ cchem-86-3-0302

VIGANÓ, J; BRUMER, I. Z.; BRAGA, P. A. C.; SILVA, J. K.; MARÓSTICA JÚNIOR, M. R.; et al. Pressurized liquids extraction as an alternative process to readily obtain bioactive compounds from passion fruit rinds. Food And Bioproducts Processing, [S.L.], v. 100, p. 382-390, 2016. Disponível em: <http://dx.doi.org/10.1016/j.fbp.2016.08.011>. DOI: 10.1016/j.fbp.2016.08.011

WEN, C.; ZHANG, J.; ZHANG, H.; DZAH, C. S.; ZANDILE, M.; et al. Advances in ultrasound assisted extraction of bioactive compounds from cash crops - A review. Ultrasonics Sonochemistry, [S.L.], v. 48, p. 538-549, 2018._Disponível em: $<$ http://dx.doi.org/10.1016/j.ultsonch.2018.7.018>. 10.1016/j.ultsonch.2018.7.018

WENG, M.; LI, Y.; WU, L.; ZHENG, H.; LAI, P. Effects of passion fruit peel flour as a dietary fibre resource on biscuit quality. Food Science And Technology, [S.L.], v. 
41, n. 1, p. 65-73, 2021. Disponível em: <http://dx.doi.org/10.1590/fst.33419>. DOI: $10.1590 /$ fst. 33419

WHO; FAO. Diet, Nutrition and the Prevention of Chronic Diseases. [S.I.]: WHO Library, $2002 . \quad$ Disponível em: <https://apps.who.int/iris/bitstream/handle/10665/42665/WHO_TRS_916.pdf>. Acesso em: 03 ago. 2021.

WIKIERA, A.; MIKA, M.; STARZYNSKA-JANISZEWSKA, A.; STODOLAK, B. Endoxylanase and endo-cellulase-assisted extraction of pectin from apple pomace. Carbohydrate Polymers, [S.L.], v. 142, p. 199-205, 2016._Disponível em: <http://dx.doi.org/10.1016/j.carbpol.2016.01.063>. 10.1016/j.carbpol.2016.01.063

WHO - World Health Organization \& Food and Agriculture Organization . CAC/RCP 73: Code of practice for the reduction of hydrocyanic acid ( $\mathrm{HCN})$ in cassava and cassava products. [S.I.]: Who Library, 2013. Disponível em: <http://www.fao.org/3/bt511e/bt511e.pdf>. Acesso em 04 ago. 2021.

WHO - World Health Organization \& Food and Agriculture Organization. CAC/RCP70: Code of practice for the prevention and reduction of ethyl carbamate contamination in stone fruit distillates. [S.I.]: WHO Library, 2011. Disponível em: $<$ https://www.gov.si/assets/organi-v-sestavi/UVHVVR/Varna-hrana/Onesnazevala-vzivilih/Etilkarbamat-zganje-CAC-RCP-70-2011.pdf>. Acesso em 04 ago. 2021.

ZIBADI, S.; FARID, R.; MORIGUCHI, S.; LU, Y.; FOO, L. TY.; et al. Oral administration of purple passion fruit peel extract attenuates blood pressure in female spontaneously hypertensive rats and humans. Nutrition Research, [S.L.], v. 27, n. 7, p. 408-416,. 2007. Disponível em: <http://dx.doi.org/10.1016/j.nutres.2007.05.004>. DOI: 10.1016/j.nutres.2007.05.004 